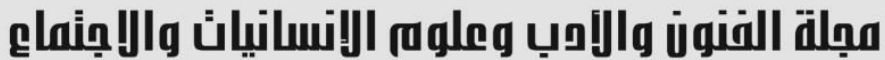

Journal of Arts, Literature, Humanities and Social Sciences www.jalhss.com

\section{تصنيف الاشكال الأرضية الناتجة من العمليات الجيومورفولوجية في اقليم الهضبة الغنبة هن النية ضمن محافظة النجف الاشرف الشغ النزي}

\author{
أ.د. نسرين عواد عبدون الجصاني

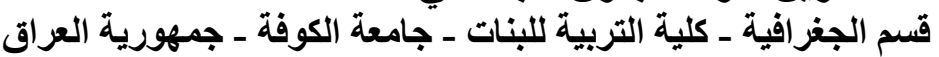 \\ الايميل: الجزية
}

ليناز هير عبد الزهرة قسم الجغر افية ـ كلية التربية للبنات ـ جامعة الكوفة ـ جمهورية العراق الايميل: alialameery32@gmail.com

|لماخص

يهدف البحث الى دراسة وتصنيف الاشكال الارضية الناتجة من العمليات الجيومورفولوجية في اقليم الهضبة الغربية ضمن محافظة النجف الاشرف التي تعد من المناطق الجافة وتتغل مساحة كبيرة من محافظة النجف الاشرف ،يضم البحث المشكلة والفرضية واهمية واهداف البحث ،وحدود منطقة البحث ،وتضمن البحث (تصنيف الاشكال الارضية في اقليم الهضبة الغربية ضمن محافظة النجف الاشرف)و الذي شمل سبعة اصناف منها اشكال ارضية الأشكال الأرضية البنيوية الحتية .الأشكال الأرضية التعروية وتضم (الاشكال التعروية المائية والاشكال التعروية الريحية) ،و الأشكال الأرضية البنائية (الارسابية ) وتضم ( الأشكال الأرضية الناتجة عن الارساب المائي ، الأشكال الأرضية الناتجة عن الارساب الريحي)،والأشكال الأرضية التبخيرية ،والانهيارات الارضية، والأشكال الأرضية الناتجة عن المياه الجوفية،والاشكال الارضية الناتجة عن فعل الانسان. 


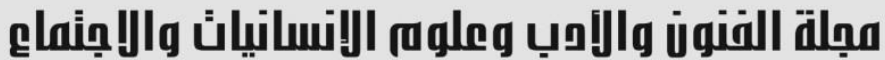 \\ Journal of Arts, Literature, Humanities and Social Sciences www.jalhss.com

\section{Classification of Terrestrial Forms Resulting from Geomorphological Processes in the Western Plateau Region within the Province of Najaf}

\author{
Prof.Dr. Nisreen Awaad Abdoon Aljassani \\ Department of Geography- Faculty of Education for Girls \\ University of Kufa- Iraq \\ E-mail: Dr.nsreen awaad@gmail.com
}

\author{
Lina Zuhair Abdulzahra \\ Department of Geography- Faculty of Education for Girls \\ University of Kufa- Iraq \\ E-mail: alialameery32@gmail.com
}

\begin{abstract}
The research aims to study and classify the ground forms resulting from geomorphological processes in the western plateau region within the province of Najaf, which is one of the dry areas and occupies a large area of the province of Najaf, includes research and problem and hypothesis and the importance and objectives of the research, and the boundaries of the research area, and included research (classification of terrestrial forms In the western plateau region within the province of Najaf (Ashraf), which included seven classes, including terrestrial shapes, terrestrial structural forms, erosive terrestrial shapes, which include (water erosion forms and wind erosive forms), and structural ground shapes (sedimentary) and include (terrestrial shapes resulting from water precipitation, shapes Ground resulting from wind precipitation), Evaporative earth shapes, landslides, terrestrial shapes caused by groundwater, and shapes grounded by human action.
\end{abstract}

Keywords: Classification of terrestrial forms, geomorphological processes, The western plateau region in Najaf. 


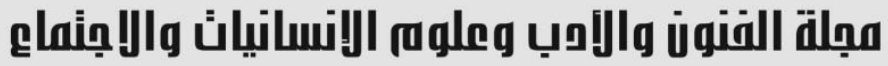

Journal of Arts, Literature, Humanities and Social Sciences www.jalhss.com

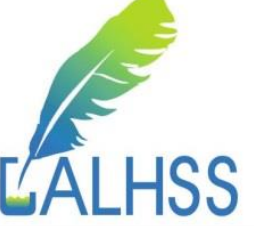

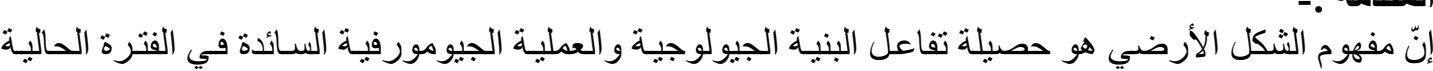

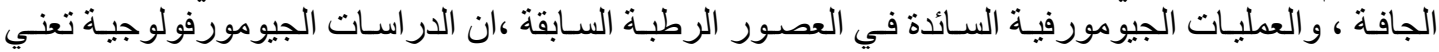

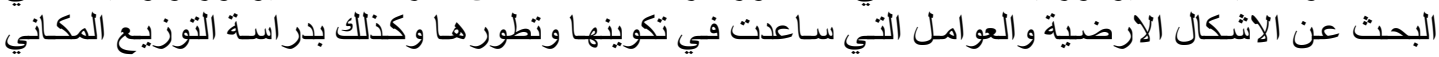

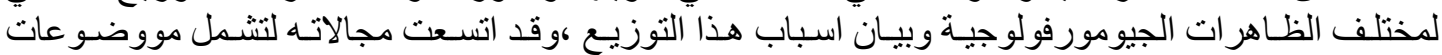

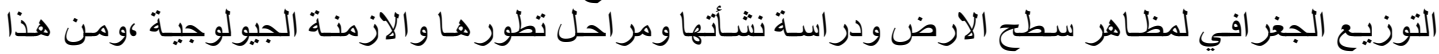

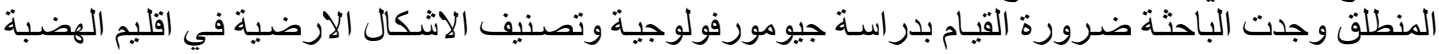
الغربية ضمن محافظة النجف الاشرف لما تتميز به هذه المنطقة من تنوع للاشكال الارضية متنوعة الارفية

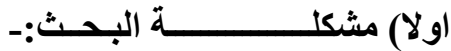

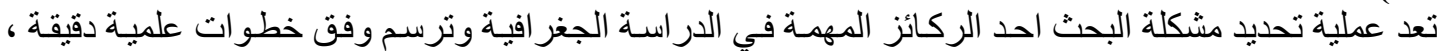

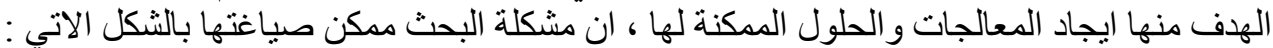

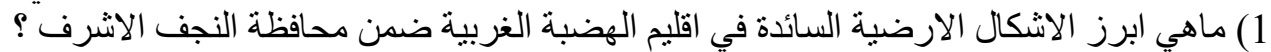
2) هل يظهر تنو ع بالاشكال الارضية وفقال لطبيعة القوة المسبية له ؟

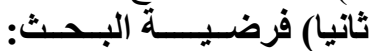

تعرف الفرضية بانها عبارة عن تخمين او استتناج ذكي يتوصل اليه الباحث ويتمسك به به بشكل مؤقت مستندا

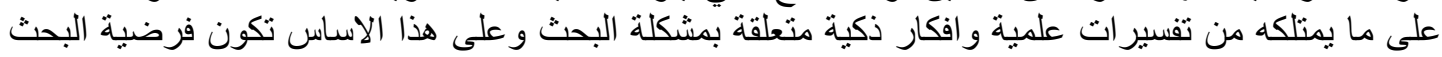

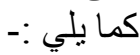

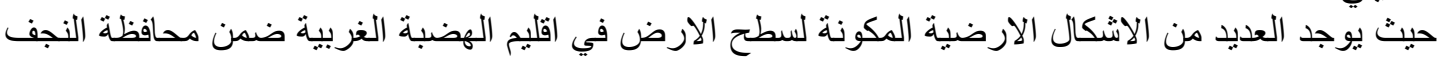

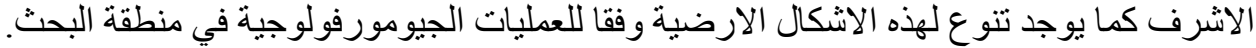

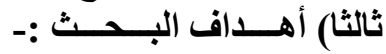

يهدف البحث إلى التعرف على تصنيف الاشكال الارضية الموجودة في أقليم الهضبة الغربية ضمن محافظة

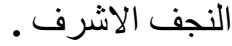

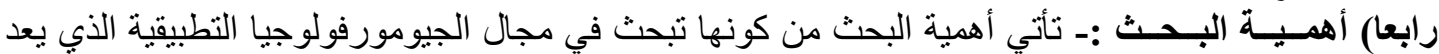

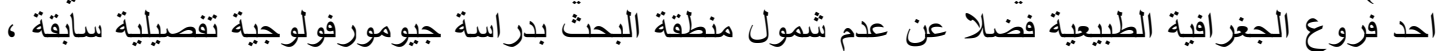

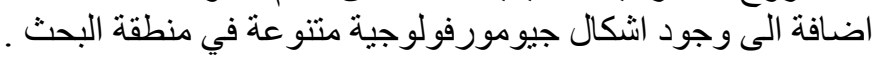

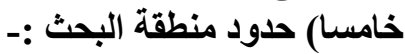
تقع منطقة البحث في الجزء هُ الجنوبي الغربي من محافظة النجف الأشرف بمسافة (240 كم) ، تحدها محافظة

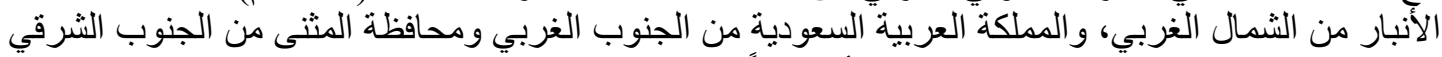

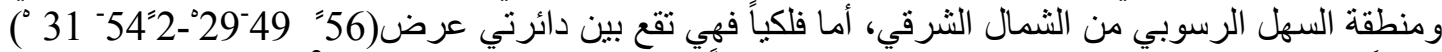

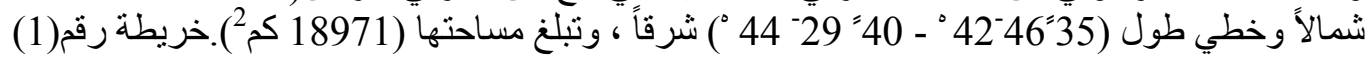

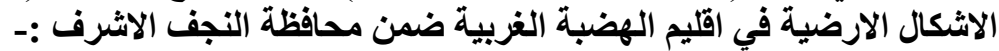

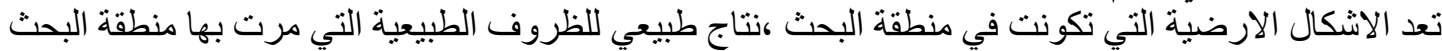

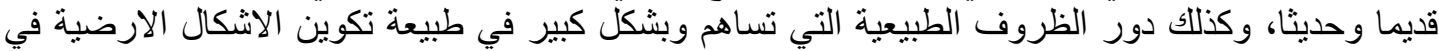

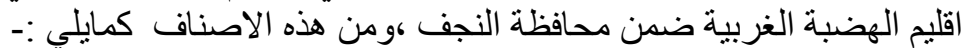

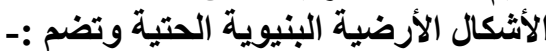

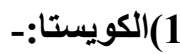

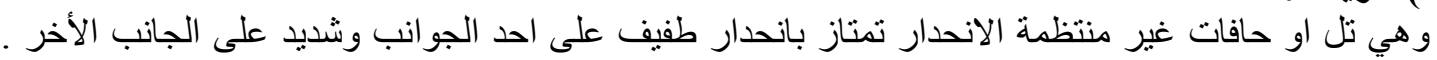

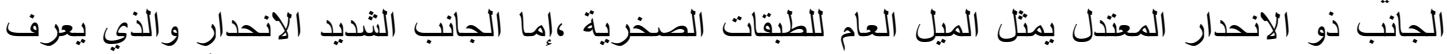

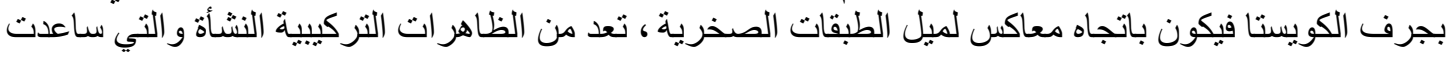

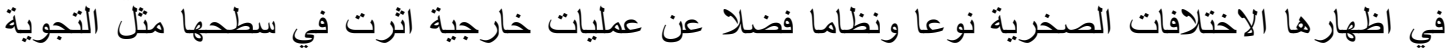

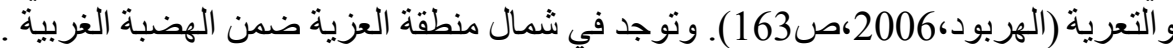




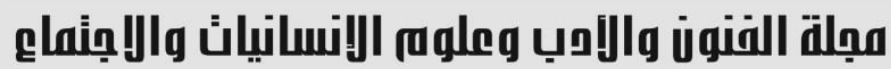

Journal of Arts, Literature, Humanities and Social Sciences www.jalhss.com

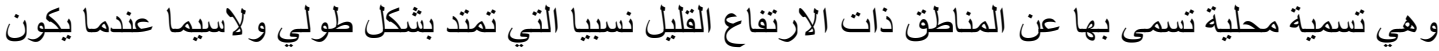

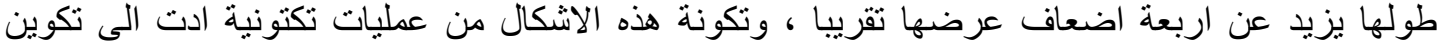

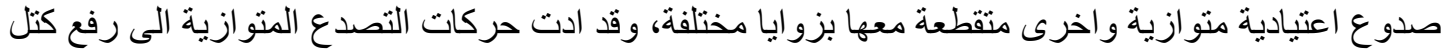

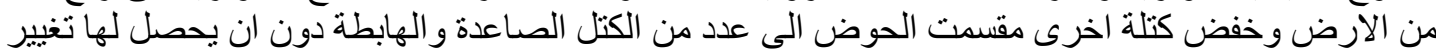

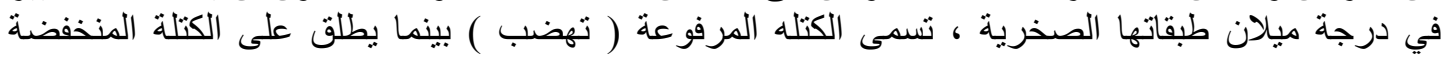

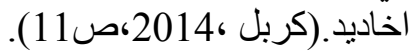
الموائد الصخرية :- ويطلق عليها (الميسا او الهضييات او الكار ات) و هي أثكال أرضية مستوية السطح ، تتكون

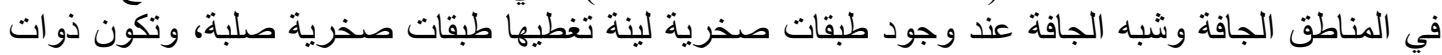

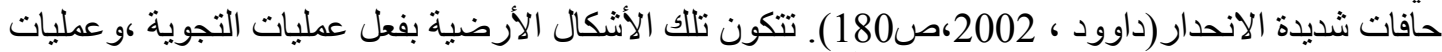

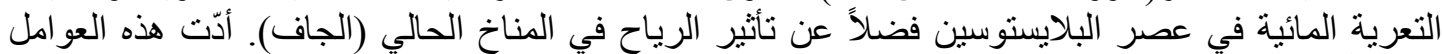

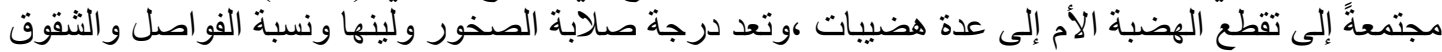

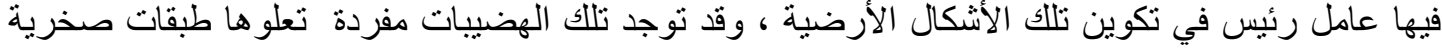

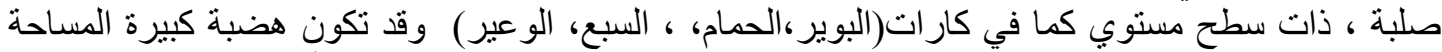

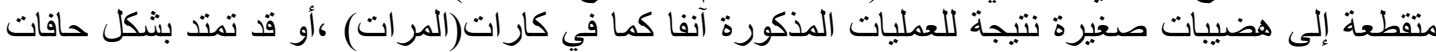

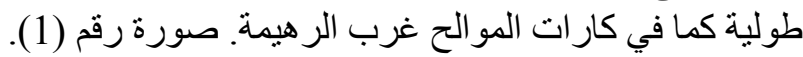




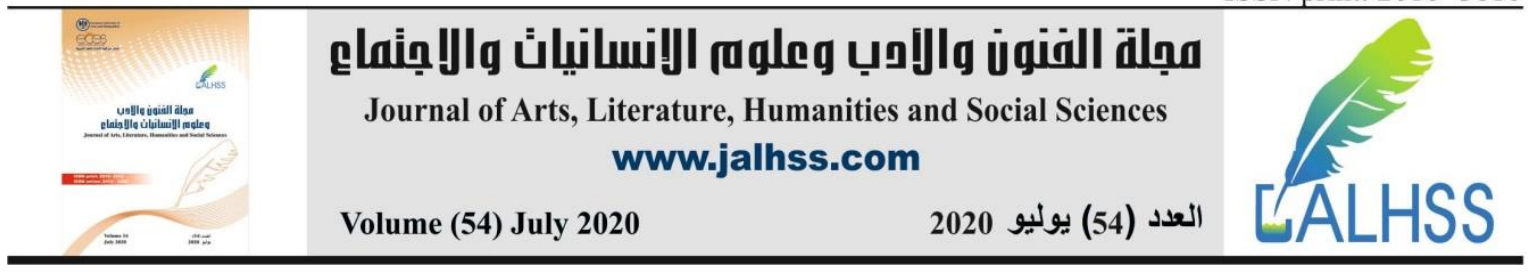

خريطة (1) الحدود الادارية وموقع منطقة البحث من محافظة النجف الاشرف

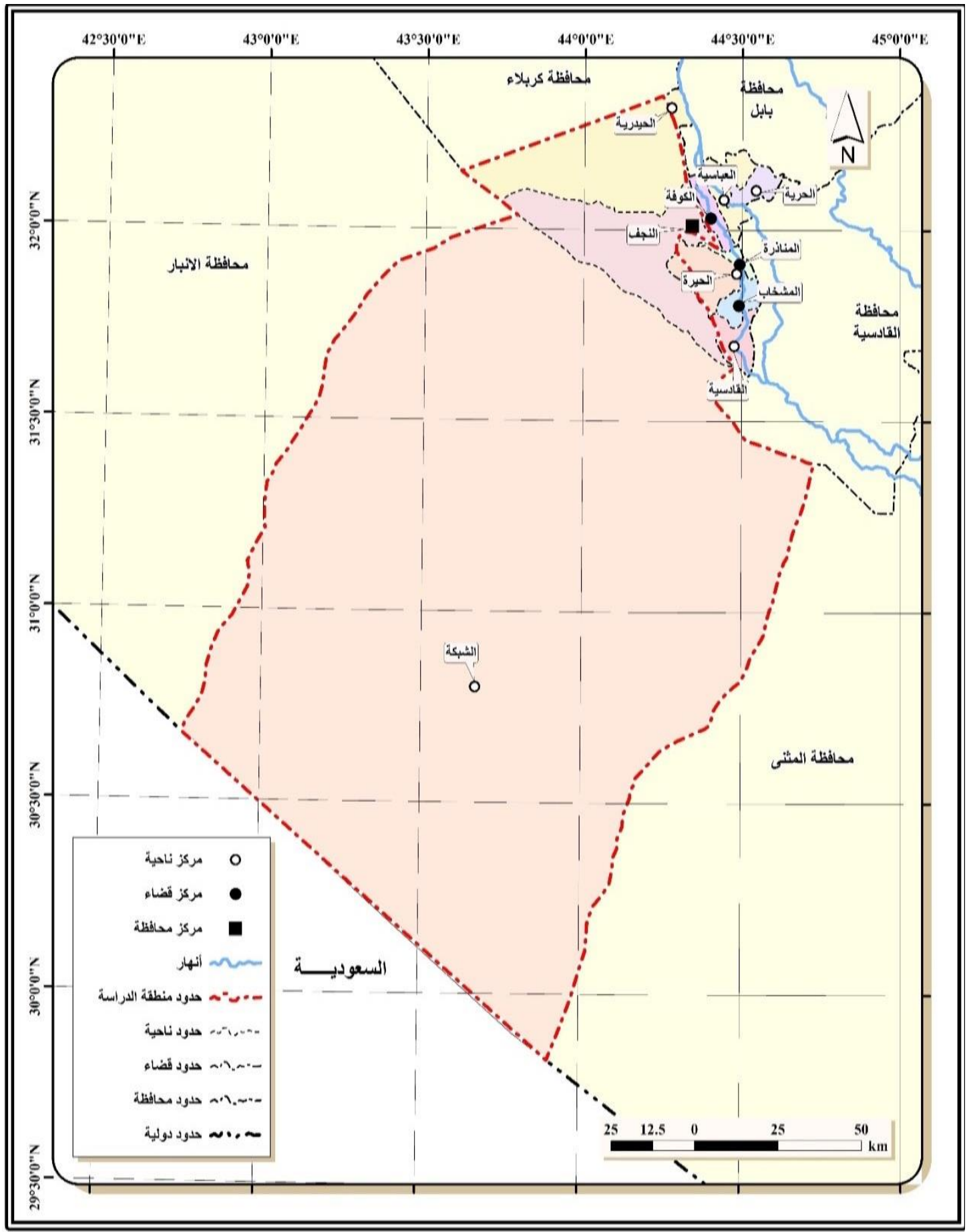

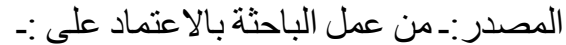

الهيئة العامة للمساحة العر اقية ، خريطة العر اق الطبو غر افية لسنة 2011، مقياس 1000000/1 


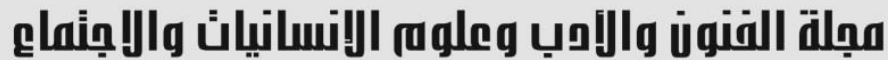

Journal of Arts, Literature, Humanities and Social Sciences www.jalhss.com

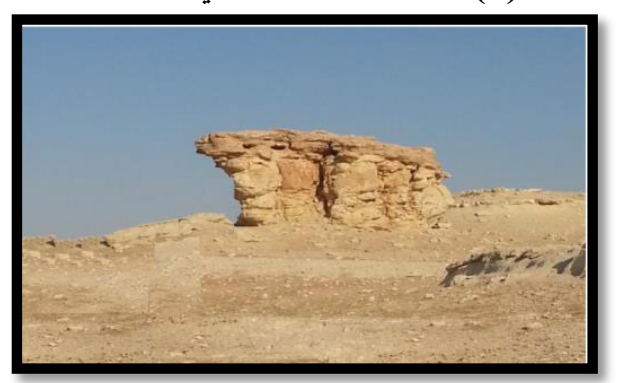

المصدر :- الدر اسة الميدانية بتأريخ 2019/2/6

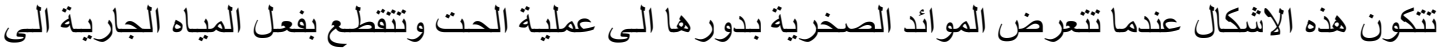

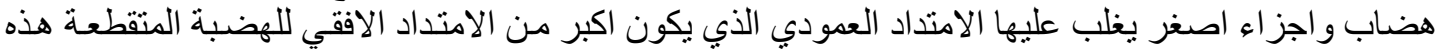

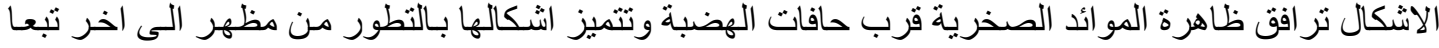

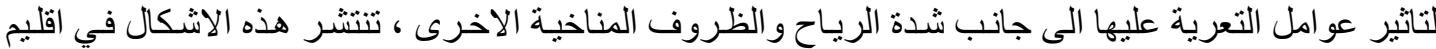

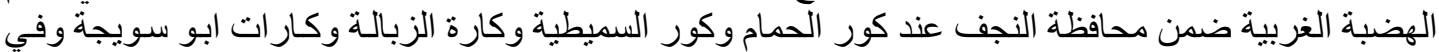

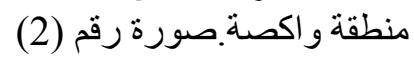
صورة (2)الشاهد الصخري

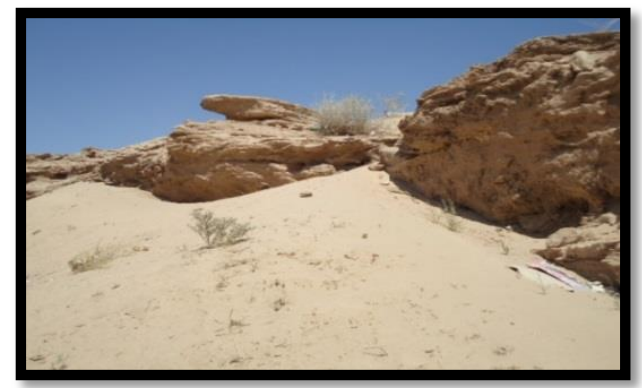

المصدر :-مـالدر اسة الميدانية 2019/2/6.

5) البيــوت :- ويطلق عليها محليا الكار ات وهي نتبه في نكوينها الموائد الصخرية الا انها اصغر حجمنـا منها

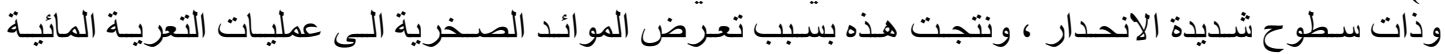
والريحية (الزيارة الميدانية التي قامت بها الباحثة بتاريخ 2019/2/5) .صورة بـرة رقم (3)

صورة (3) ظاهرة البيوت في منطقة اللصف

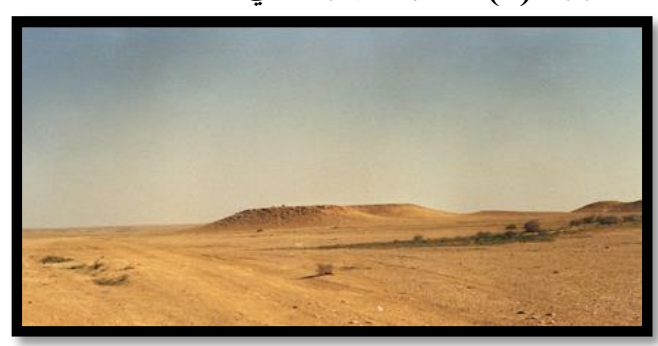




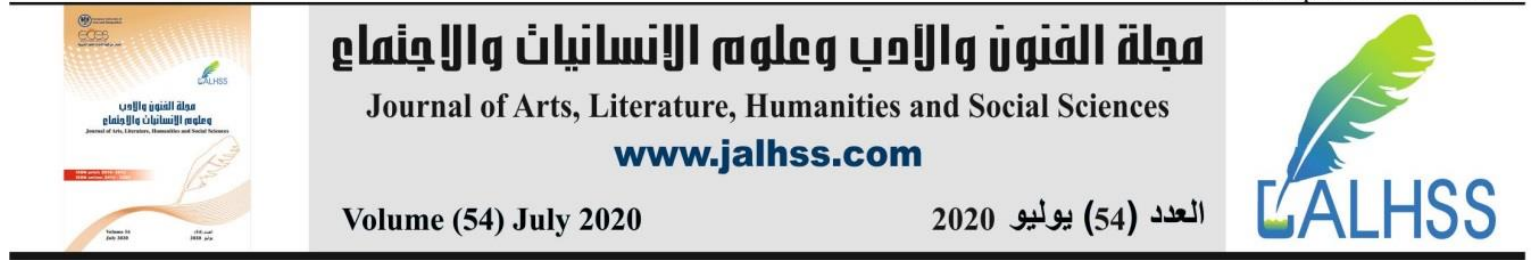

المصدر:-- الدر اسة الميدانية 2019/2/5

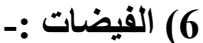

تتصف الفيضات بكونها أر اضي منبسطة قلبلة الانحدار، قد يتوسطها بئر أو مجموعة آبار ،تتباين في مسـاحاتها

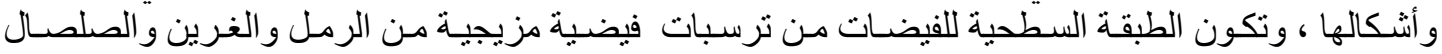

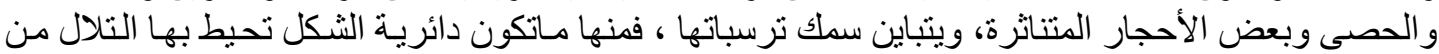

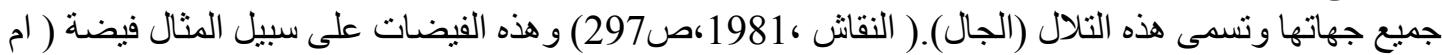

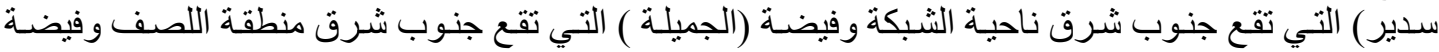

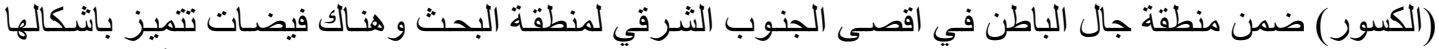

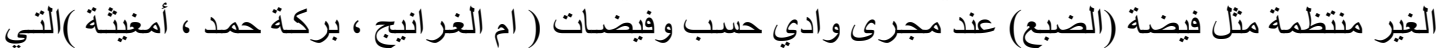

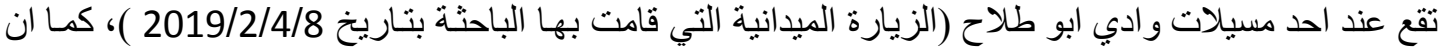

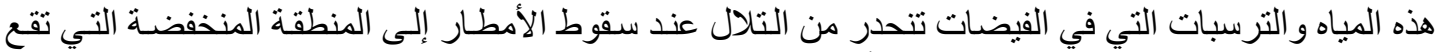

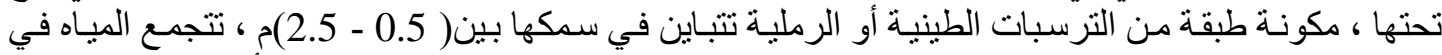

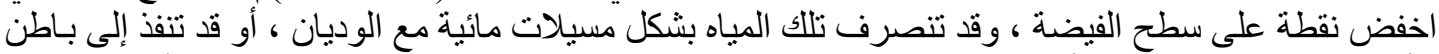

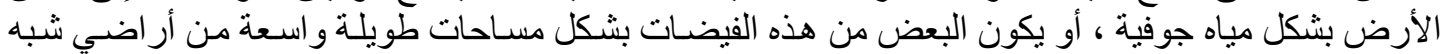

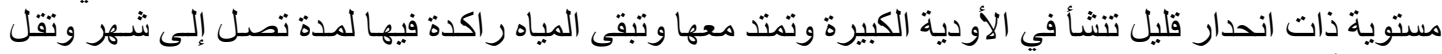

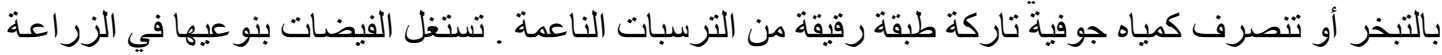

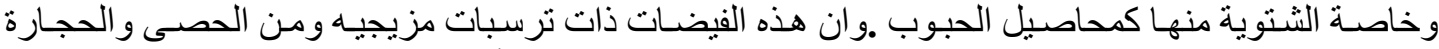

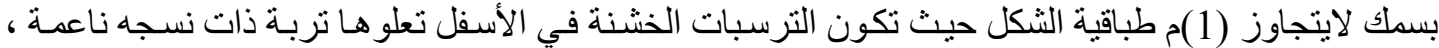

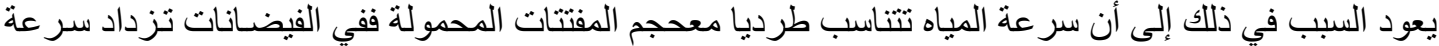

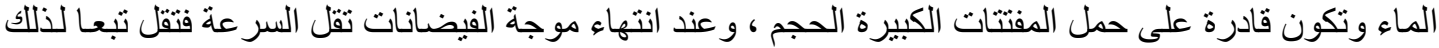
حجم المفتتات ،أو قد يعود السبب إلى تجمع المياه الحاملة للترسبات الخشنة في هذه المناطق فتكون كمسنويً

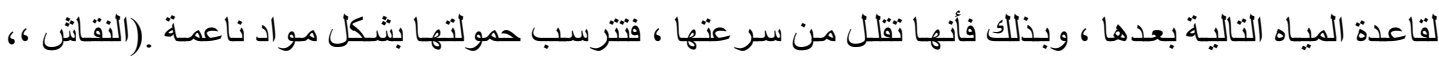

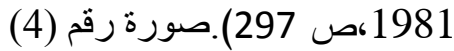

صورة (4) فيضة الليفية وسط منطقة البحث

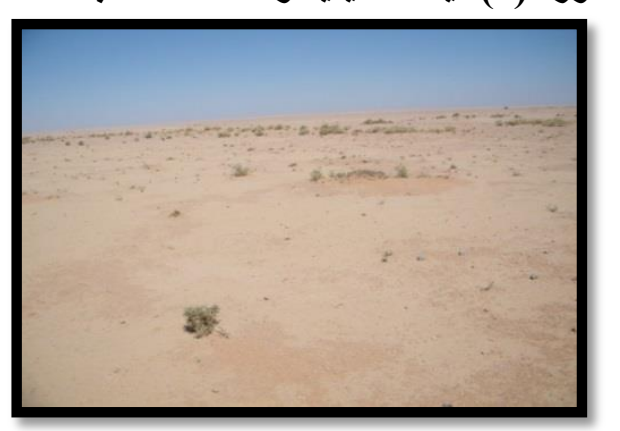

2019/4/8 المصدر :- الدر اسة الميدانية بتأريخ

الأشكال الأرضية التعروية وتضم :-

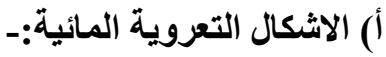

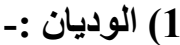

تعد الوديان اهم الاشكال الارضية الموجودة في منطقة البحث والتي تكونة بفعل الامطار الغزيرة خلال العصور

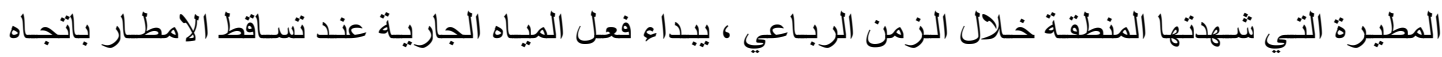

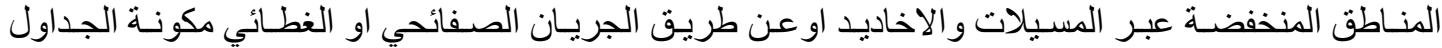




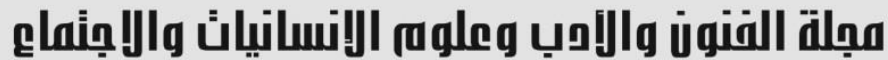

Journal of Arts, Literature, Humanities and Social Sciences www.jalhss.com

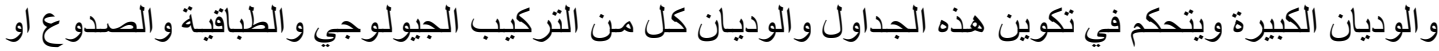

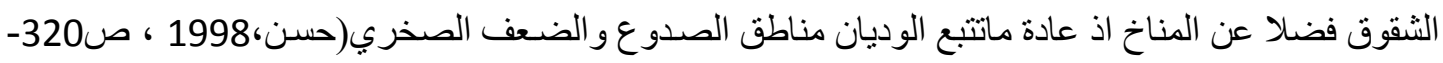

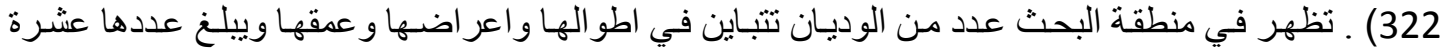

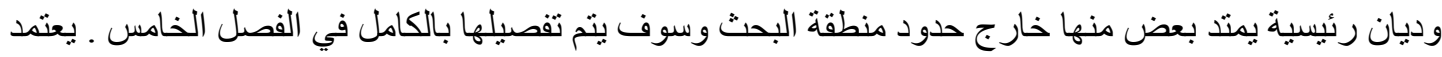

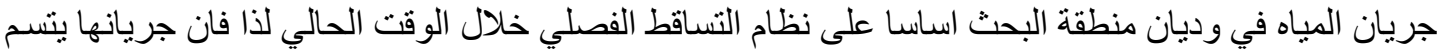

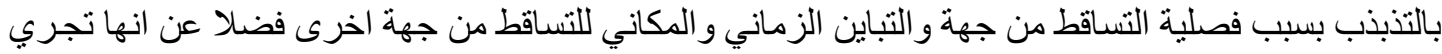

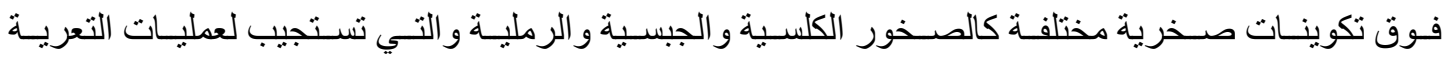

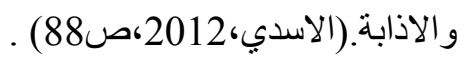

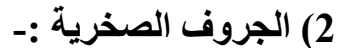

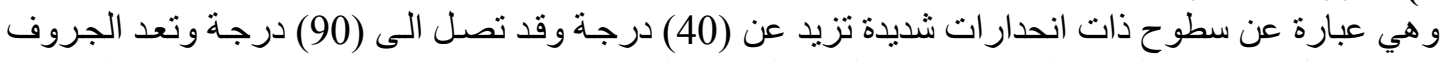

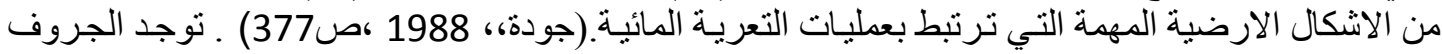

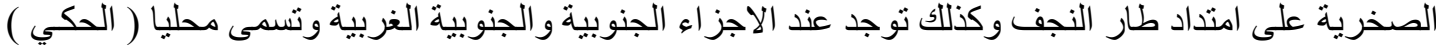

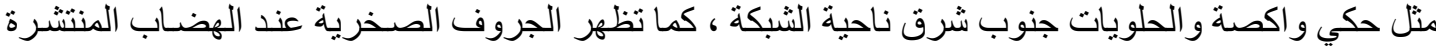

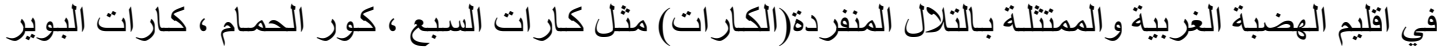

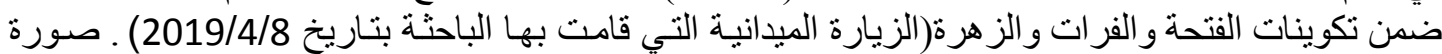

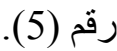

\section{صورة (5) جرف صخري في منطقة غرب منطقة الشبكة}

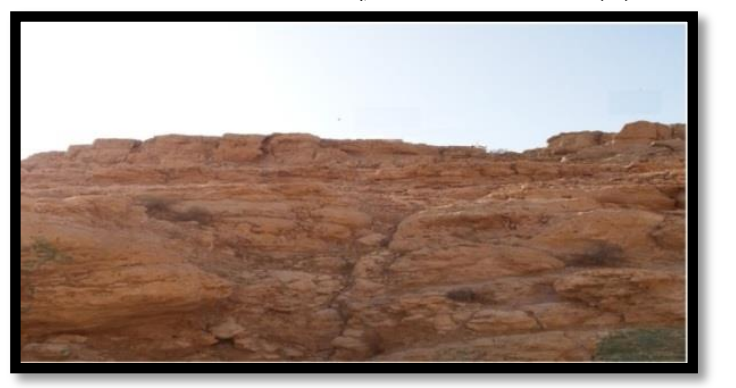

2019/4/8 المصدر :الدر اسة الميدانية بتاريخ

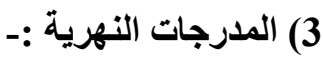

ان تفسير نشوء ظاهرة المدرجات النهرية تقوم على نظريتان النظريـة الاولى تقول ان هذه الظـاهرة ذات اصل النس

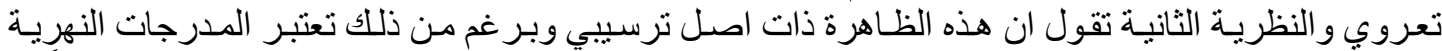

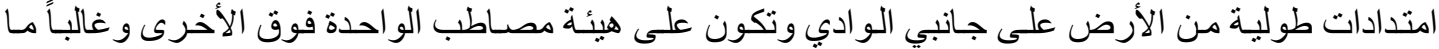

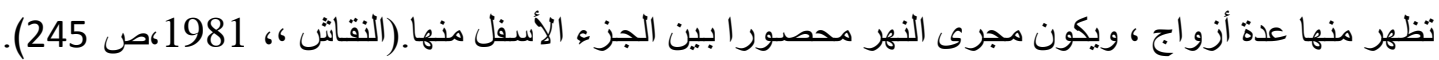

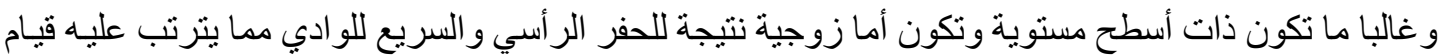

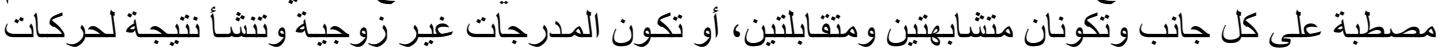

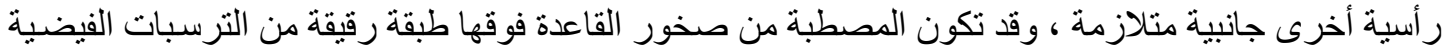

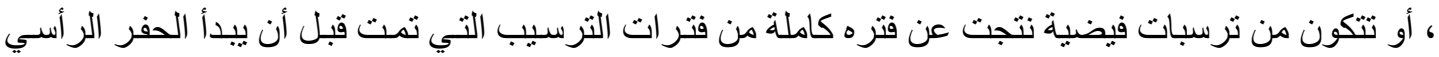

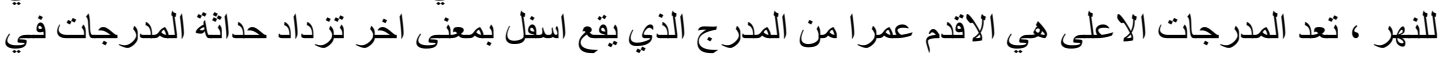

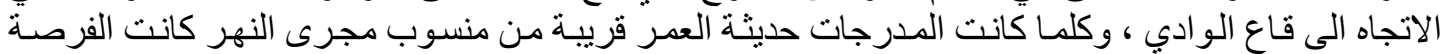

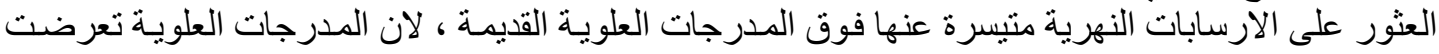

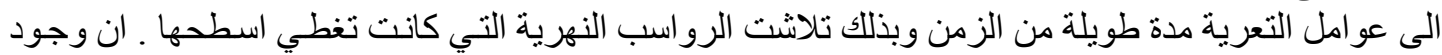




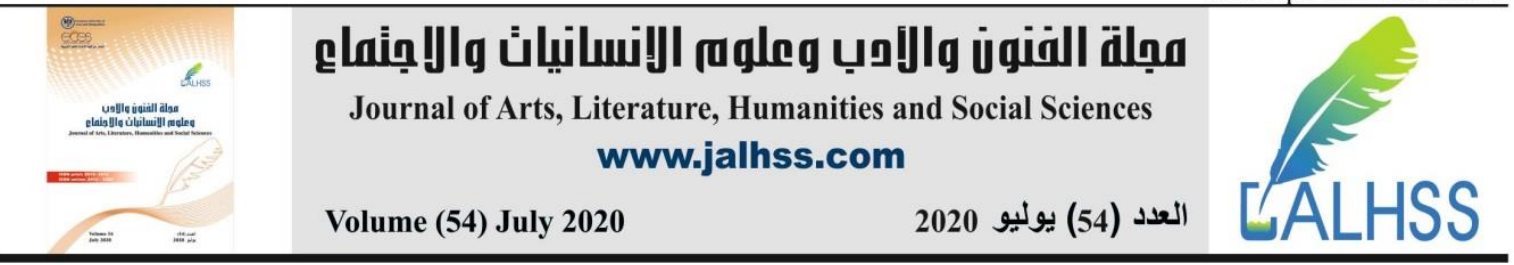

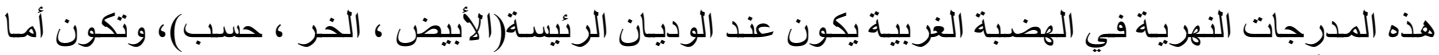

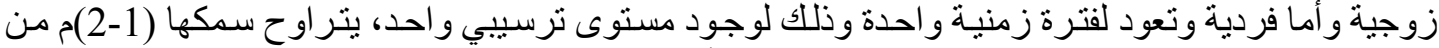

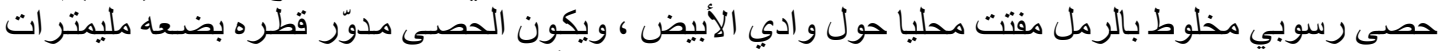

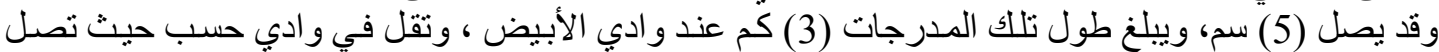

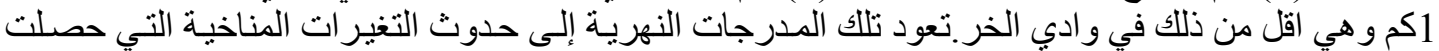

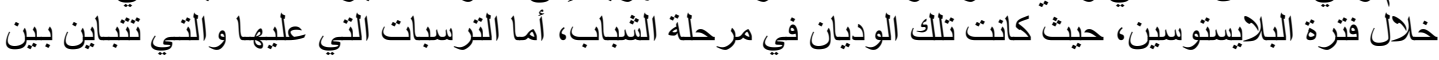

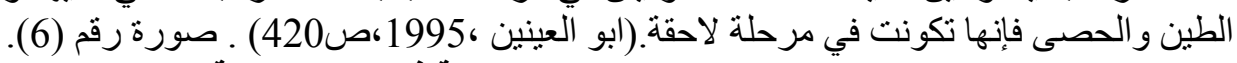
صورة (6).المدرجات النهرية في شرق الثبكة

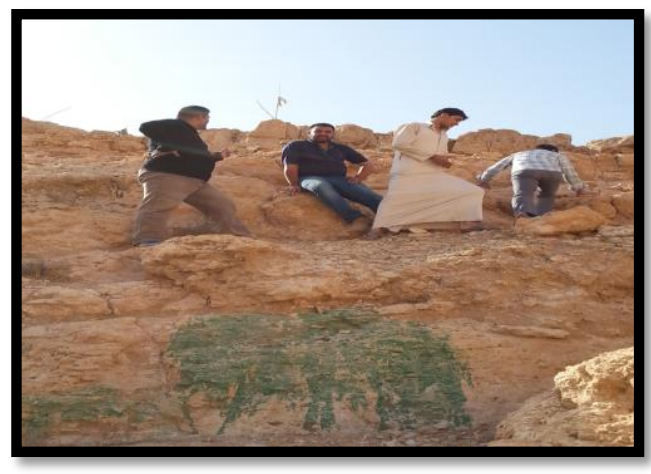

2019/2/6 المصدر :- الدر اسة الميدانية بتأريخ

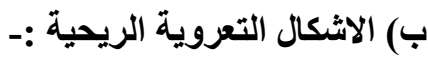

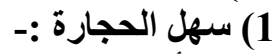

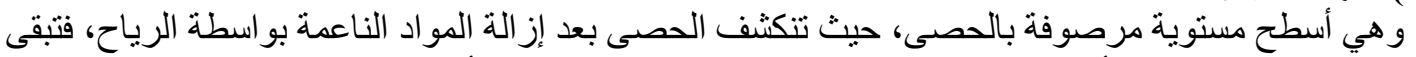

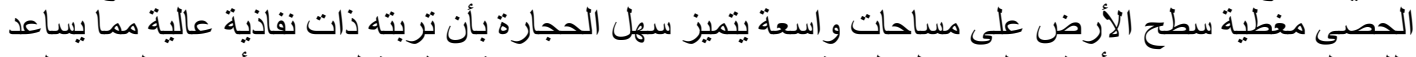

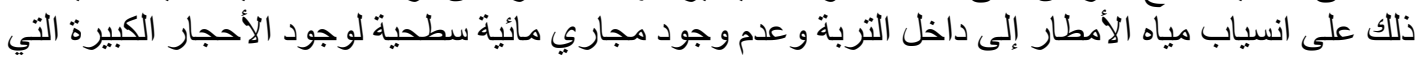

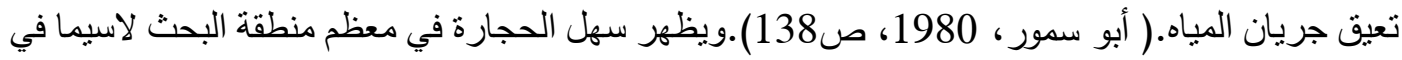
الأجز اء الجنوبية والجنوبية الغربية الجورية صورة (7)، ولهذا سميت بمنطقة الحجارة بالنسبة للتقسيمات

صورة (7) سهل الحجارة جنوب منطقة البحث

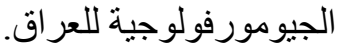

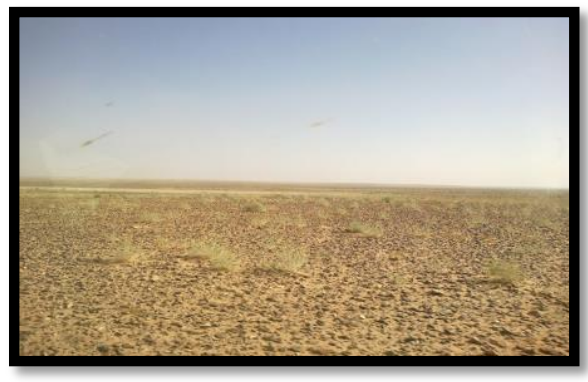

المصدر :- الدراسة الميدانية بتأريخ 2019/4/15.

2) الأرصفة الصحراوية :-

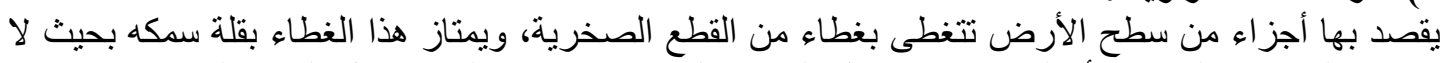

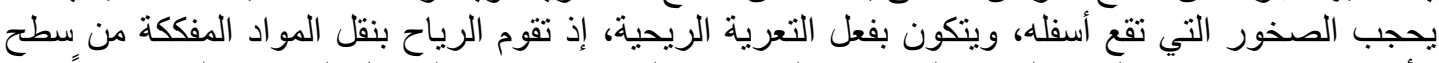

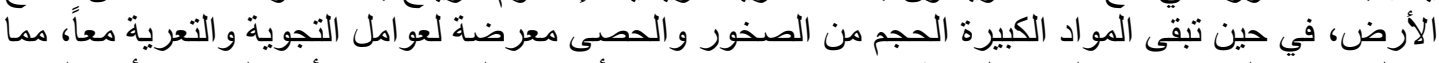

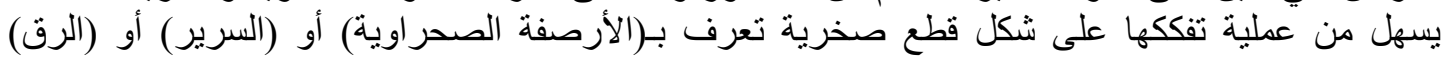




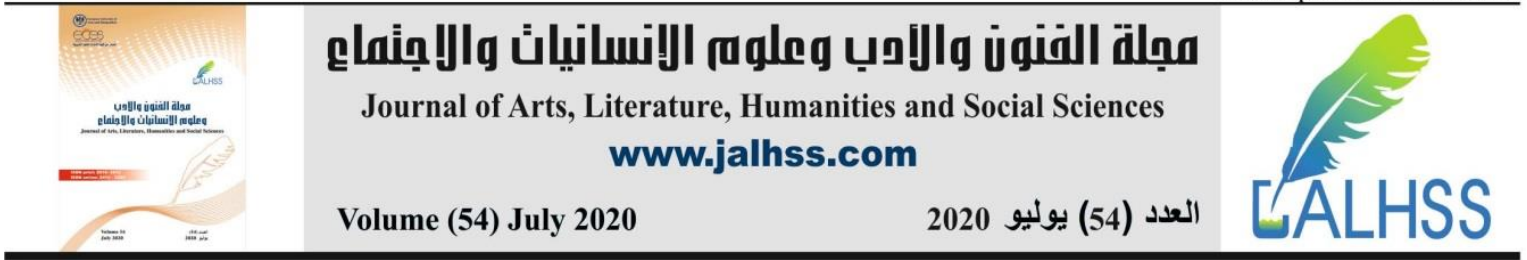

(الحديثي، 2010، صنائية 119).. نوجد هذه الظاهرة في منطقة البسيطة وسط منطقة البحث وكذلك في منطقة الربيثة باتجاه عثمين شرق الثبكة. صورة (8) صورة

صورة (8 ) الأرصفة الصحراوية في منطقة البسيطة

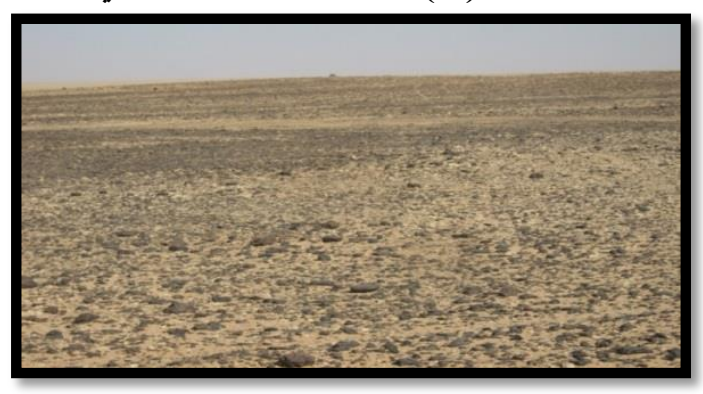

المصدر :- الدراسة الميدانية بتأريخ 2019/5/15.

3) تقوب أو كهوف الرياح:

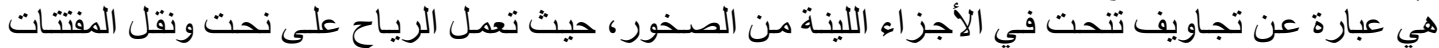

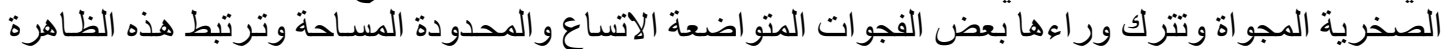

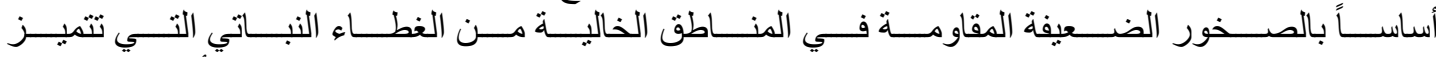

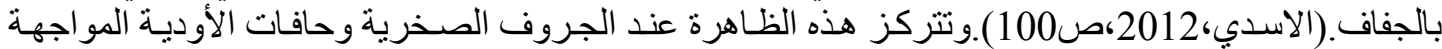

\section{صورة (9) ثقوب او كهوف الرياح في جنوب شرق منطقة البحث}

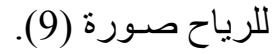

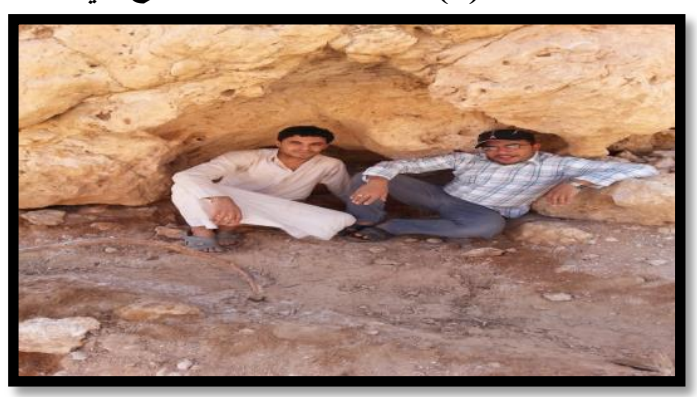

2019/5/15 المصدر :- الدر اسة الميدانية بتأريخ

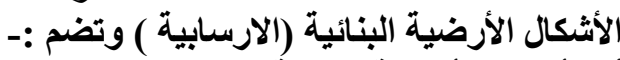

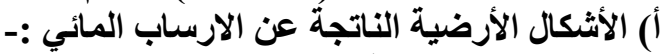

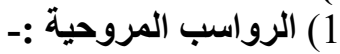

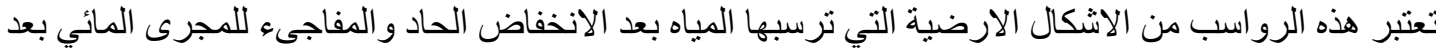

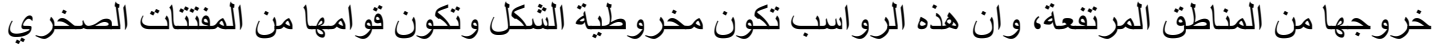

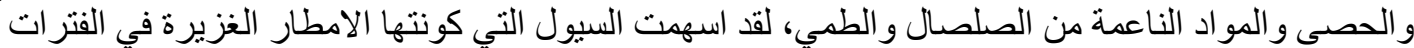
المطيرة لعصر البلايستوسين في تكوين هذه الاشكال ، و لاسيما عند طار النجف . 2) 20 رواسب قيعان الوديان:-

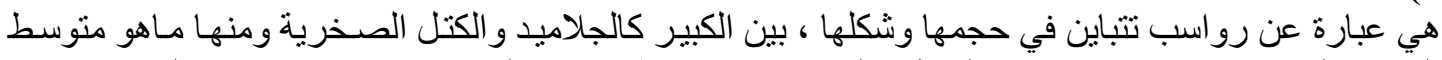

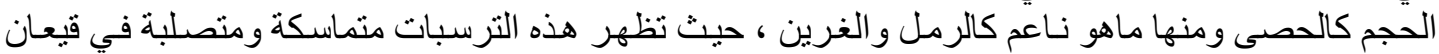

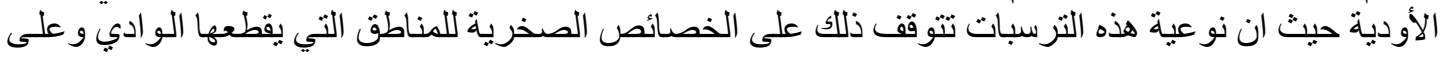

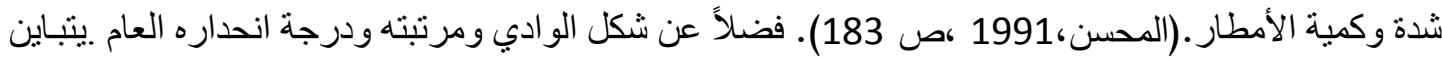

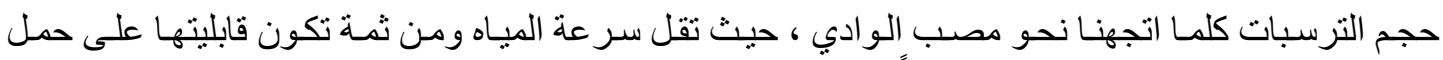
الففتتات الصـرية اقل فتترسب تدريجياً ، ويمكن ملاحظة تدرج الترسبات في الوديـان الكبيرة ، من خلالهـ 


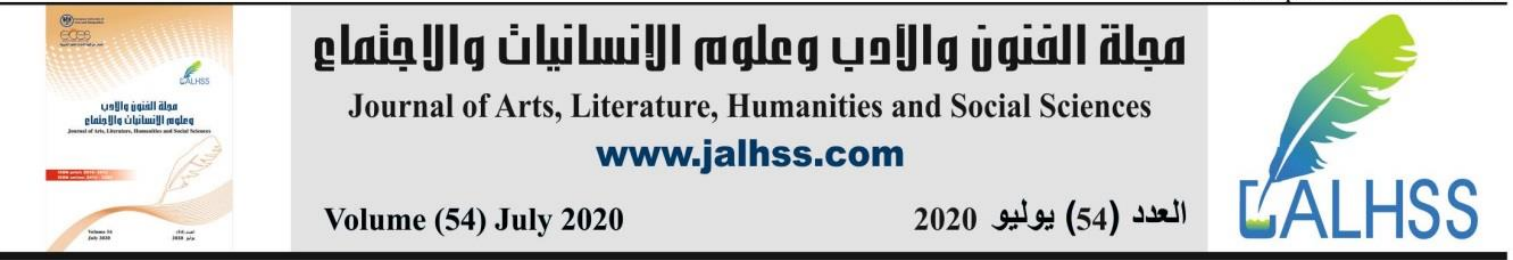

تترسب الجلاميد الصخرية ثم الحصى ثم الرمل ثم الغرين ويكوّن مقطع عميق وضيق نسبياً ، حيث يكون الو ادي الري

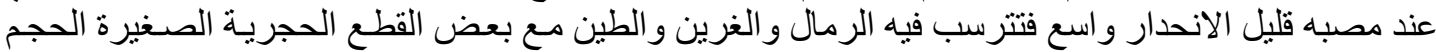

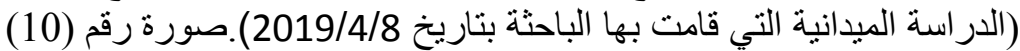
صورة (10) رواسب قاع الوادي في جنوب منطقة البحث

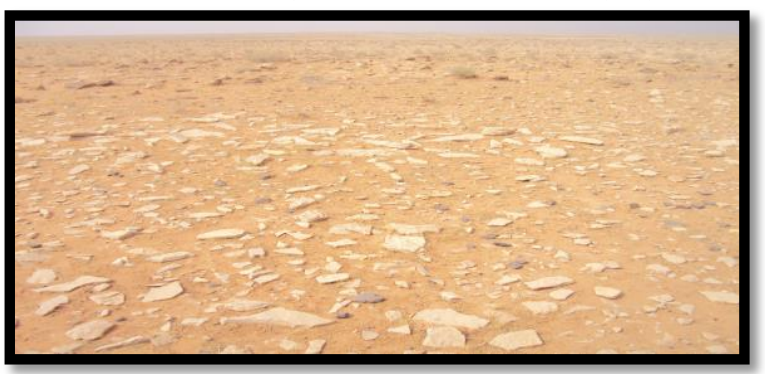

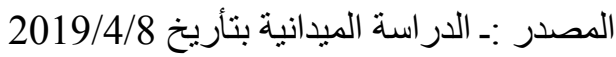

ب) الأشكال الأرضية الناتجة عن الارساب الريحي :-

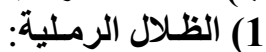

يطلق هذا التعبير على التر اكمات الرملية الصغيرة التي تتكون بنظام معين حول عقبة من العقبات، ويعتبر وجود

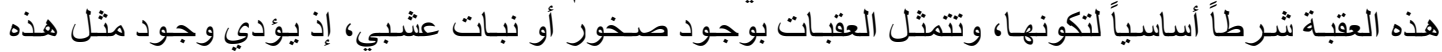

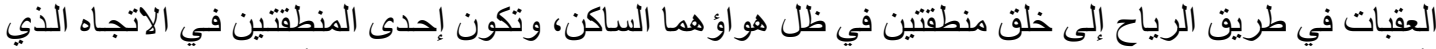

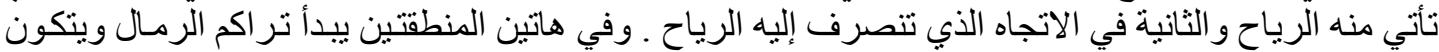

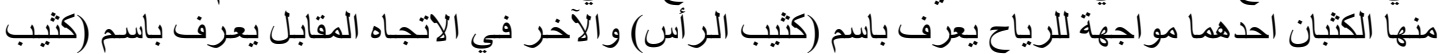

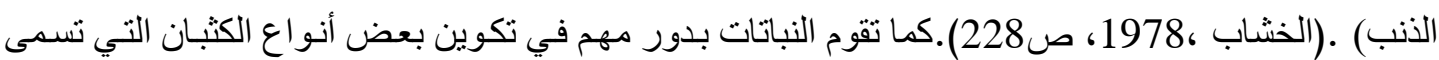

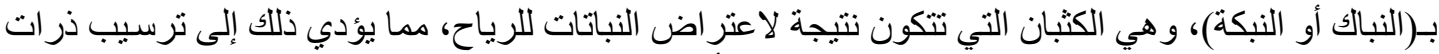

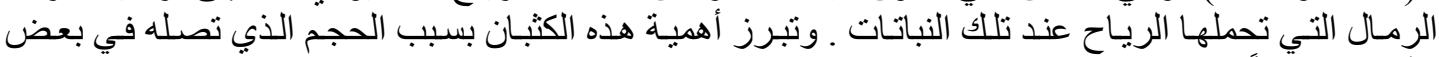

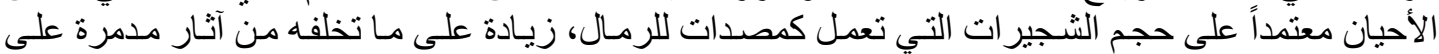

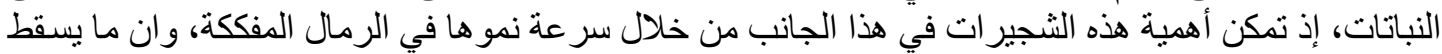

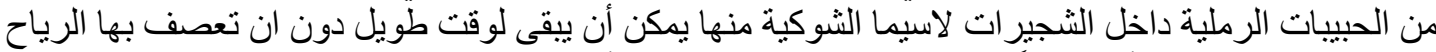

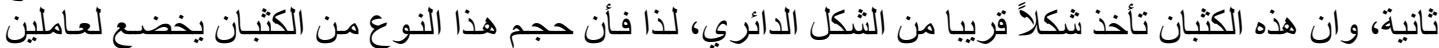

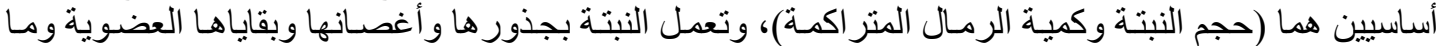

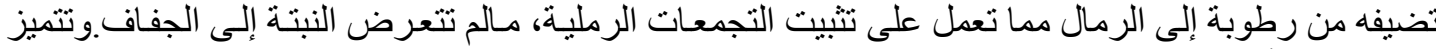

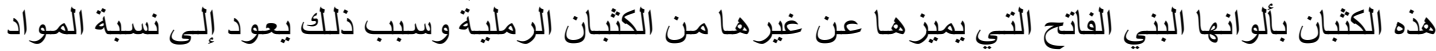

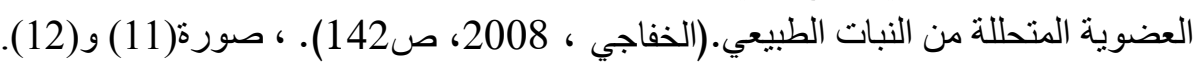




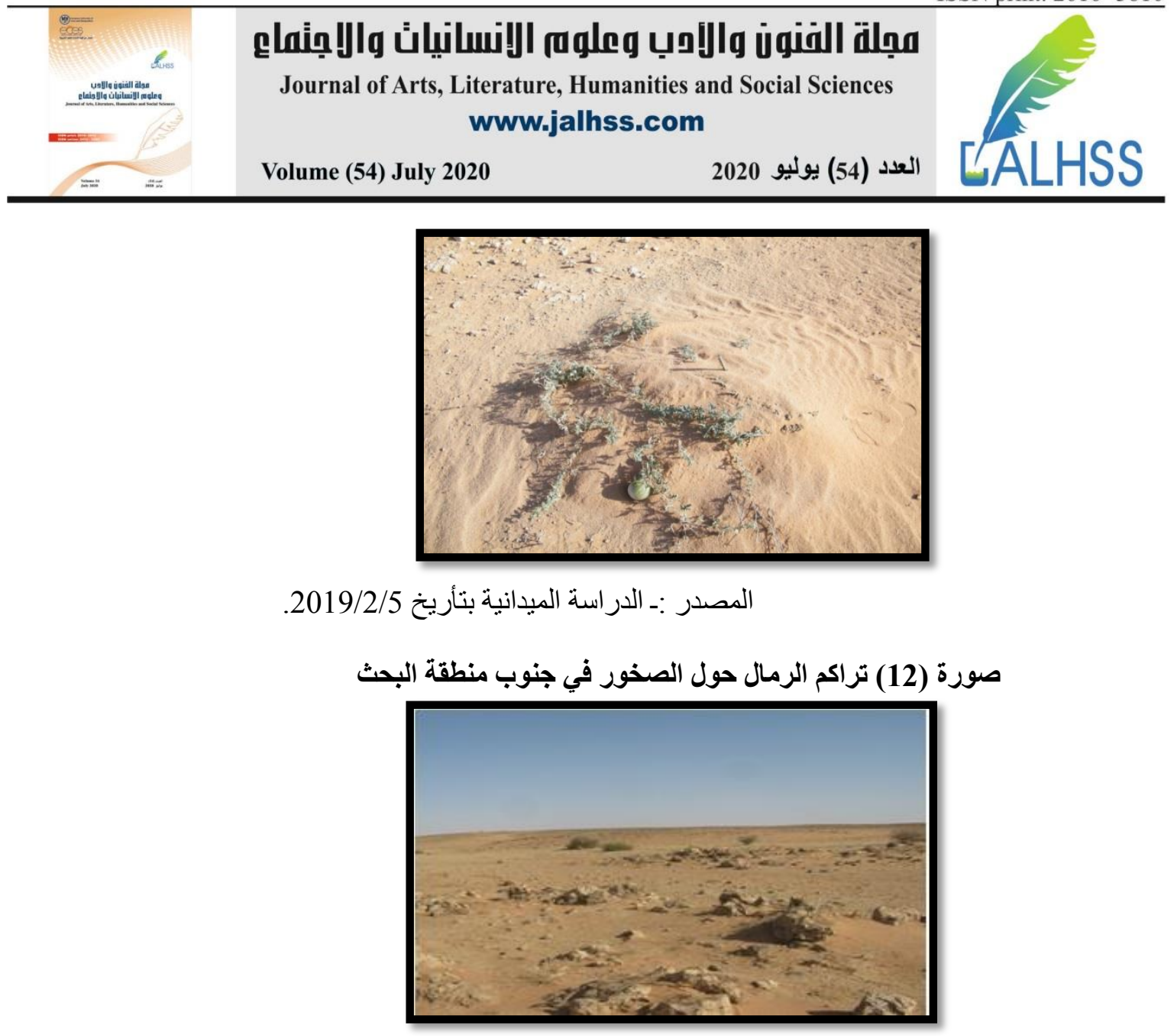

المصدر :- الدراسة الميدانية بتأريخ 2019/2/5.

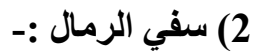

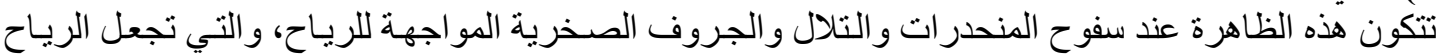

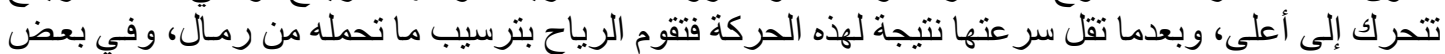

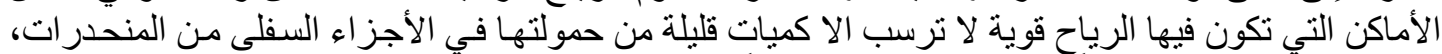

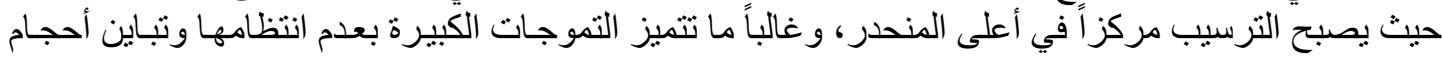

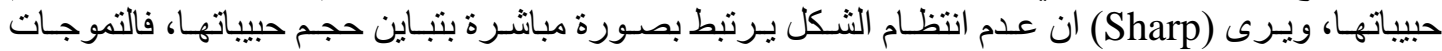

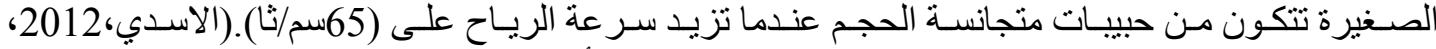

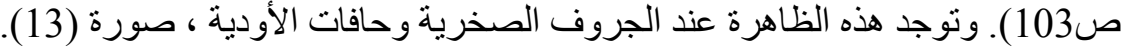
صورة (13) ظاهرة سفي الرمال في منطقة البحث

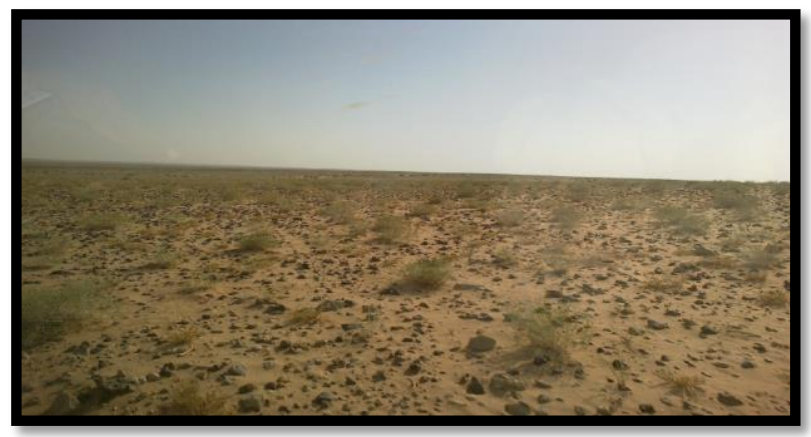

المصدر :- الدراسة الميدانية بتأريخ 2019/4/15. 


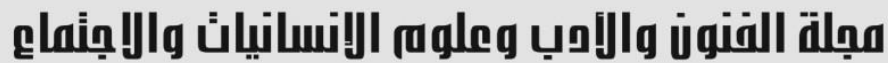

Journal of Arts, Literature, Humanities and Social Sciences www.jalhss.com

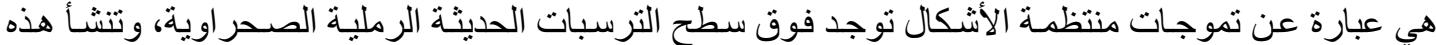

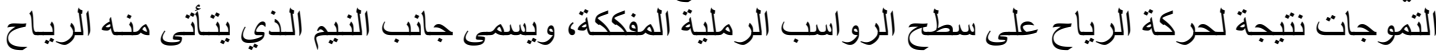

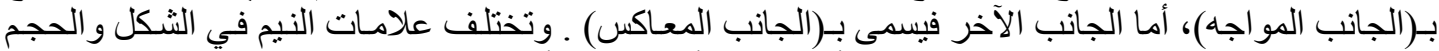

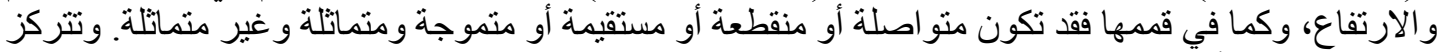
هذه الظاهرة في أجز اء محددة من منطقة الدر اسة، حيث يتر اوح ارتفاعها (4سم) صورة (14).

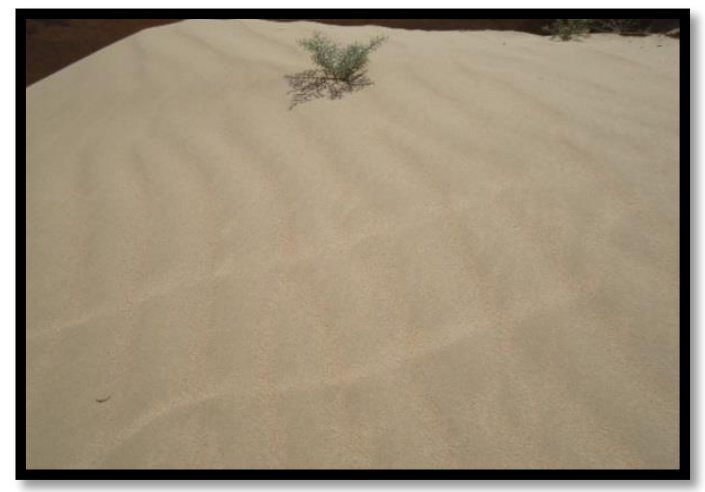

المصدر :- الدراسة الميدانية بتأريخ 2019/4/15.

ويوجد هناك أنو اع عدة من النيم منها تكون ذات تموجات منمانلة الجو انب، و عادة تكون قمتها وقيعانها مستديرة

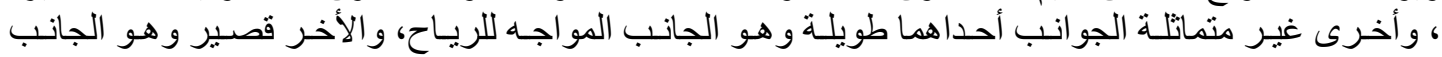

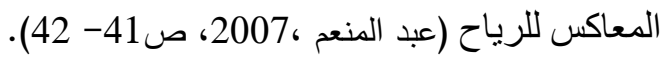

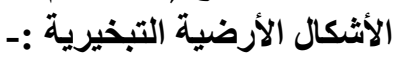

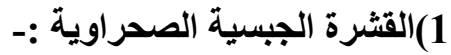

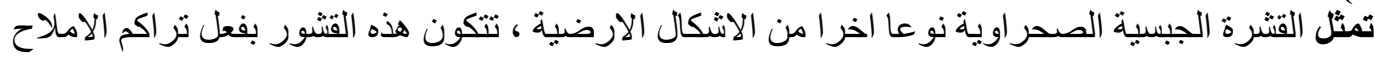

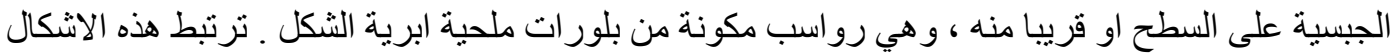

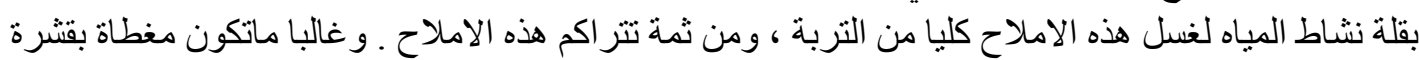

رقيقة من الترسبات الريحية والتي قد يصل سمكها الى (30) سم، ويمكن ملاحظة الاختلافات في القترة

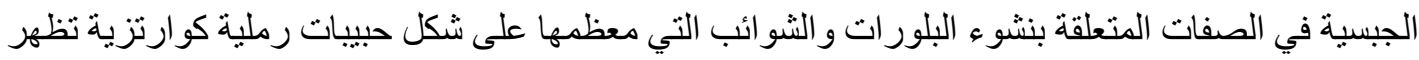
هذه الاشكال الارضية غرب منطقة الدر اسة وتتكون من الجبس الثانوي او التربة ذات النسبة العالية من الجبس ،

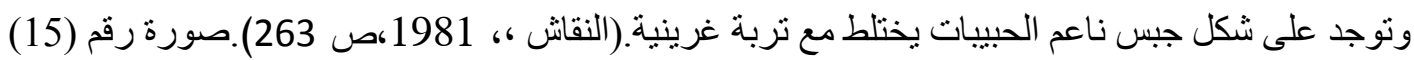
صورة رقم (15) القشرة الجبسية الصحراوية في منطقة اللصف تربه 


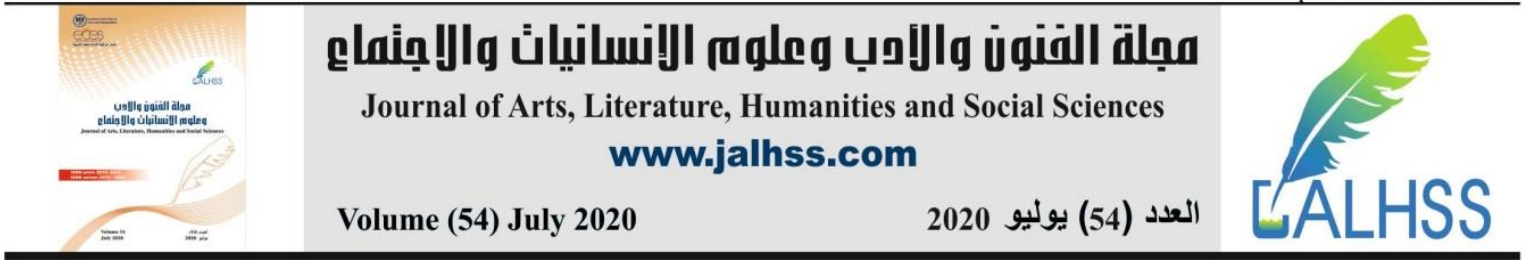

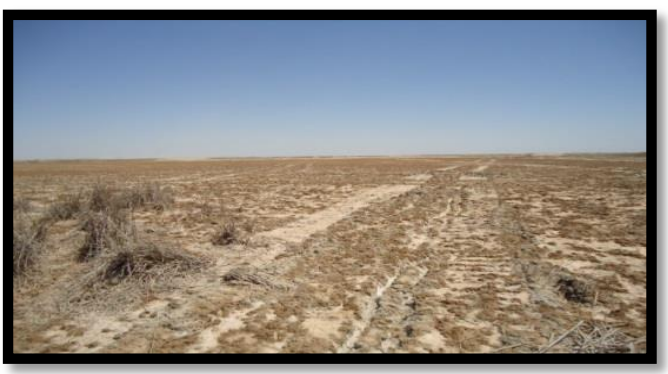

2019/2/6 المصدر :- الدر اسة الميدانية بتأريخ

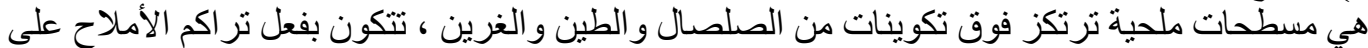

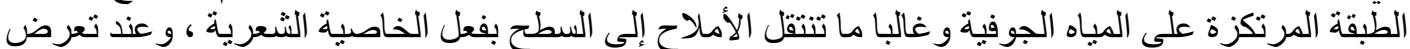

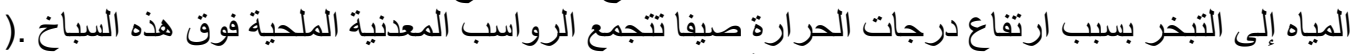

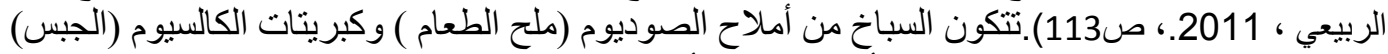

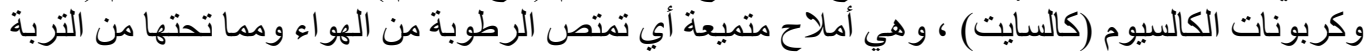

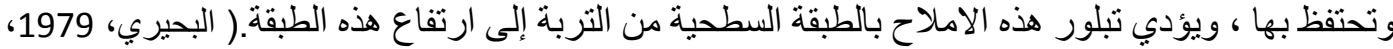

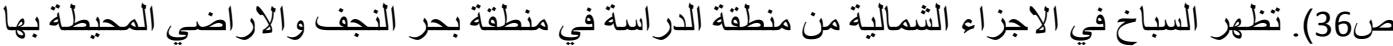
وتكون تربتها طينية منتبعة بالمياه و هي منطقة تصريف لمعظم وديان منطقة الدر اسة. (الدر اسة الميدانية بتاريخ

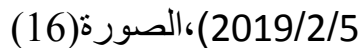

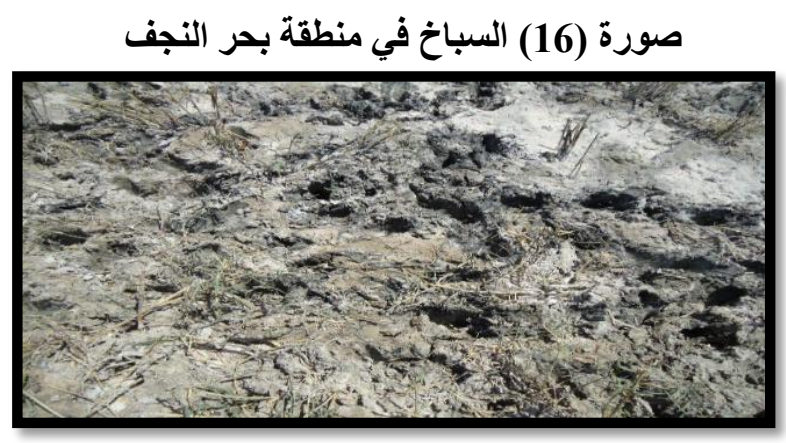

المصدر : الدر اسة الميدانية بتاريخ 2019/2/5

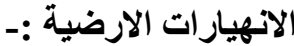

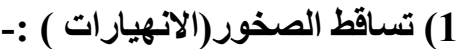

يعد التساقط الصخري من اهم الانهيار ات الارضية في منطقة البحث وهو والاته يحدث فوق السفوح الصخرية العليا

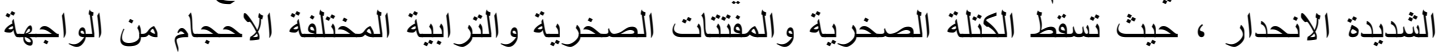

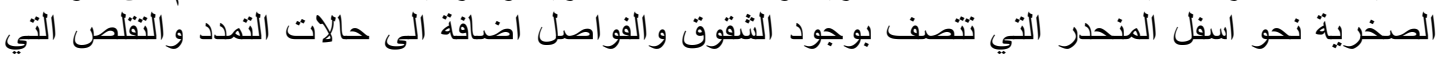

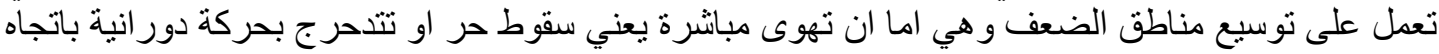

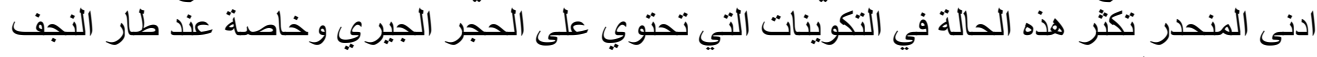

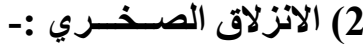

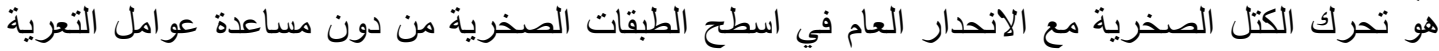

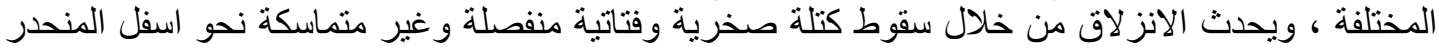

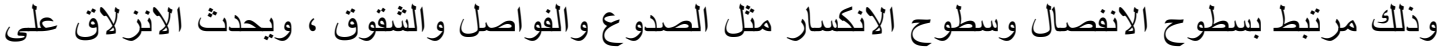

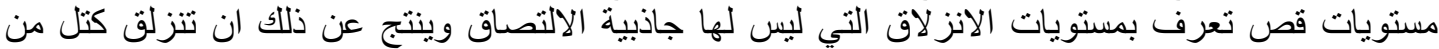

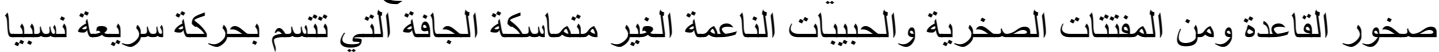




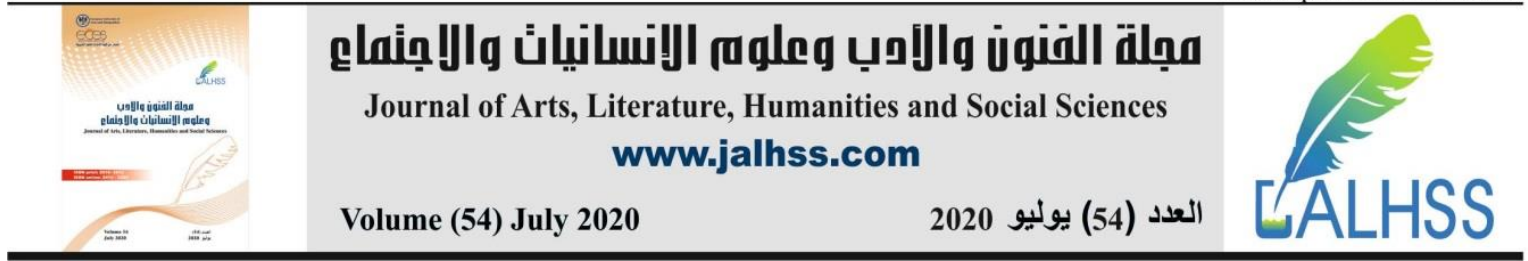

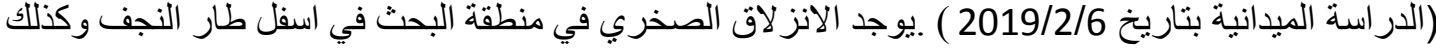

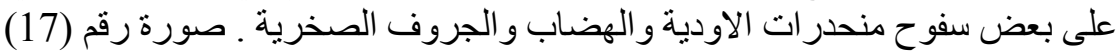
صورة (17) النزلاق الصخور

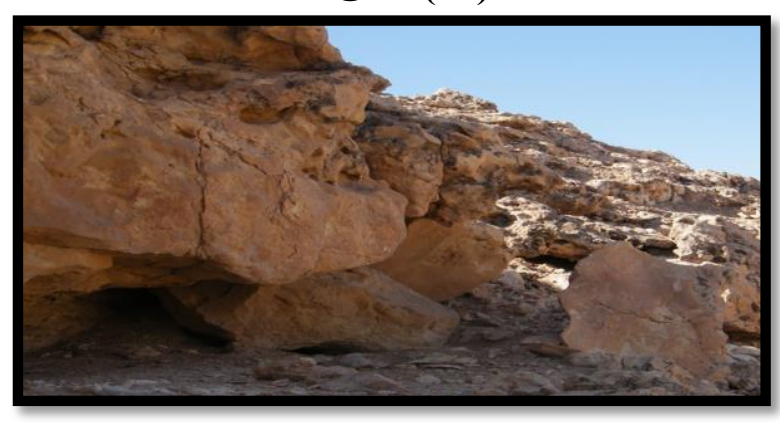

2019/2/6 المصدر :الدراسة الميدانية بتاريخ

3)الزحســـف :- تثمل كل من زحف المو اد الصخرية و الرواسب وزحف الصخور ، وهي عملية زحف بطيئة

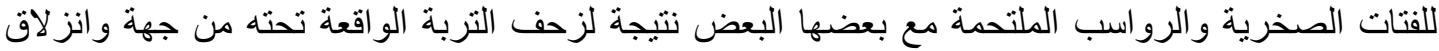

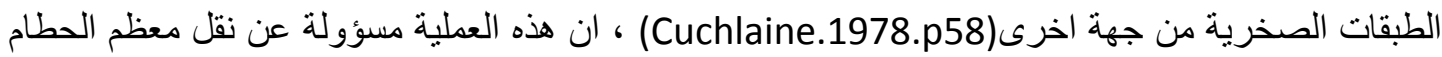

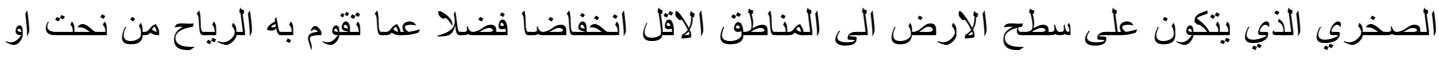

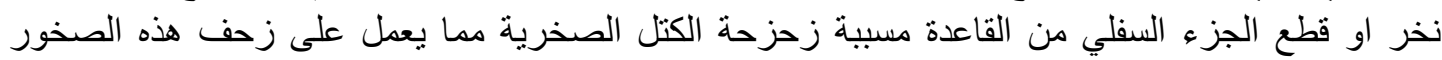

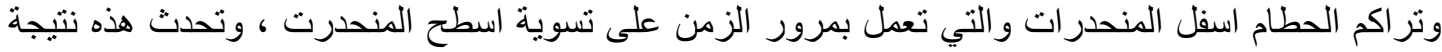
عمليات التمدد والتقلص في اتجاه يوافق ميل السفح وكذك نتيجة لنمو البلورات الملحية والطينية في الثقوق وتوالي الرطوبة والجفاف.(النقاش ،، 1981،ص 252). تكثر هذه الظاهرة عند حافات الوديان والجروف ولند الصخرية و لاسيما على امتداد طار النجف . الأشكال الأرضية الناتجة عن المياه الجوفية :-

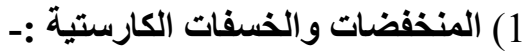

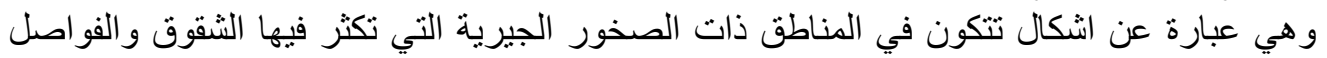

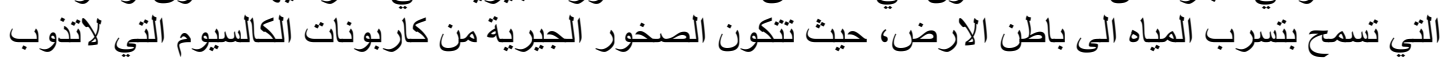

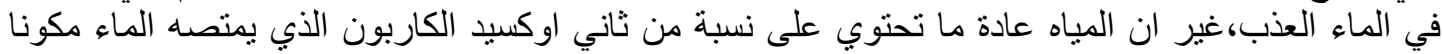

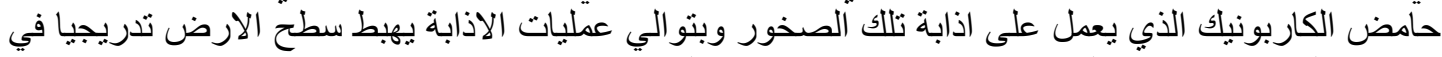

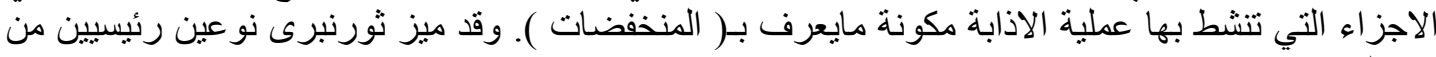

1) منخفضات تتكون تدريجيا وبيطء شديد بفعل ذوبان جزء من تكوينات الصخور الجيات الجيرية التي تقع اسفل سطح التربة مباثرة ،و لايصاحب نشأة هذه المنخفضات عمليات انهيار في الصخور التي تتطور فوقها وقد الطلق عليها

بـ من منفضات او خسفات الاذابة ). 2) منخفضات تتأثر بفعل انهيار الصخر من اسقف الكهوف اوالفجوات الباطنية واطلق عليها (منخفضات

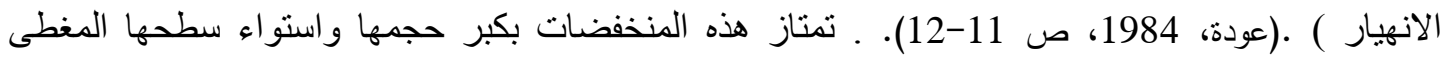

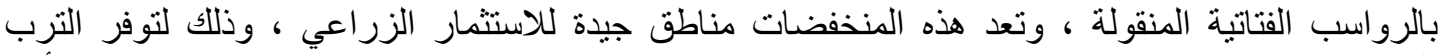

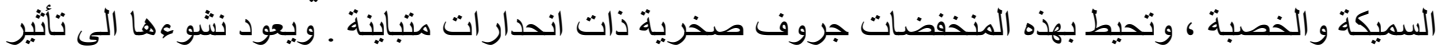

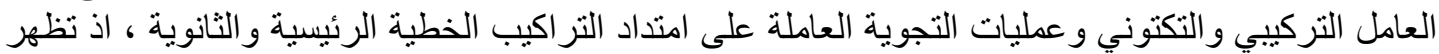

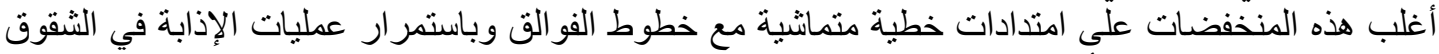

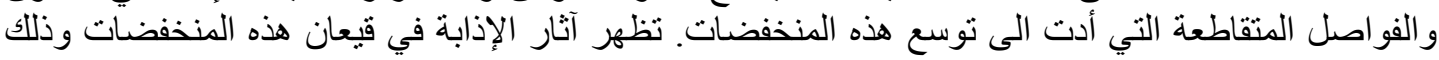




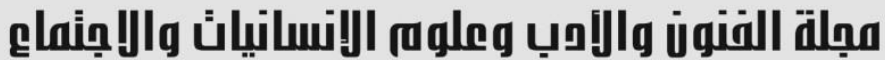

Journal of Arts, Literature, Humanities and Social Sciences www.jalhss.com

بحدوث عملية هبوط لتربة المنخفض على امتداد الفواصل والثقوق المتقاطعة التي تبدو على شكل سواقي

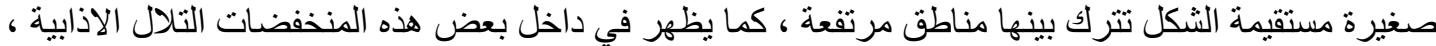

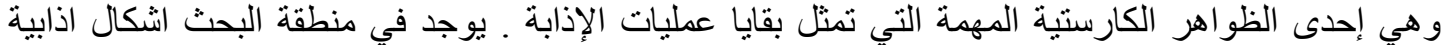

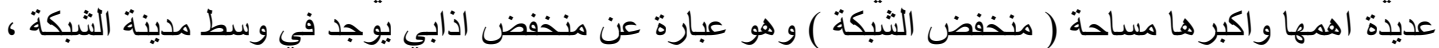

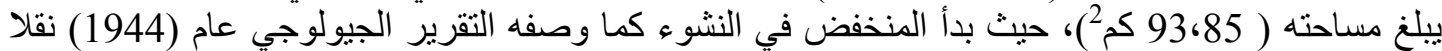

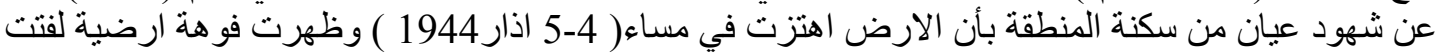

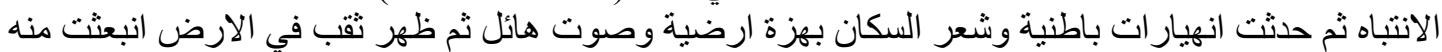

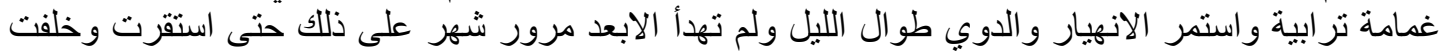

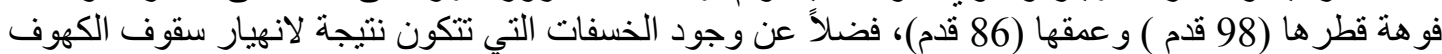

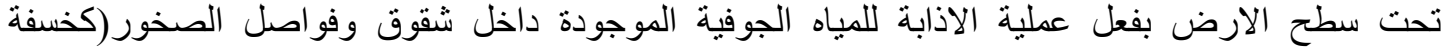

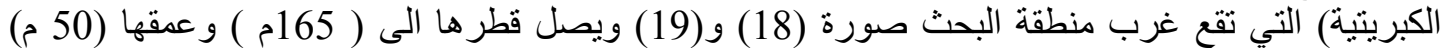

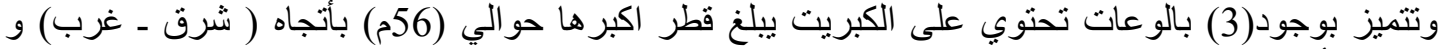

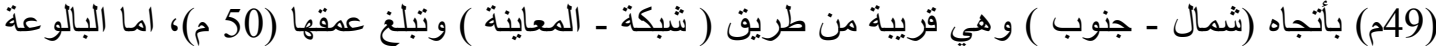

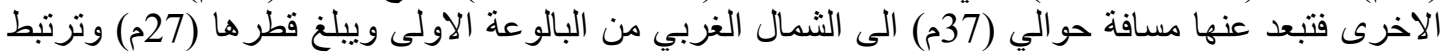

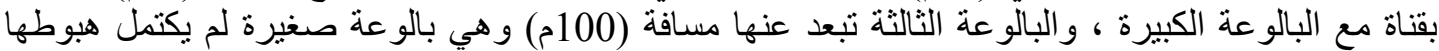

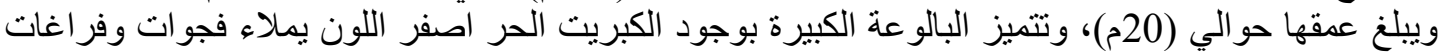

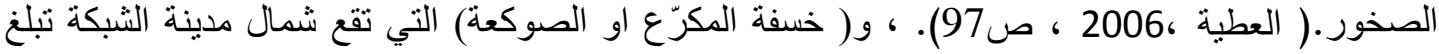

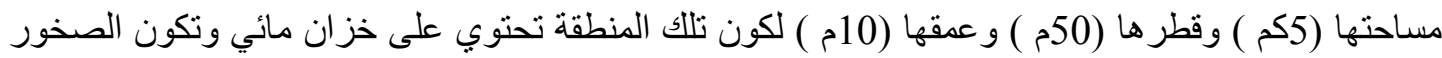

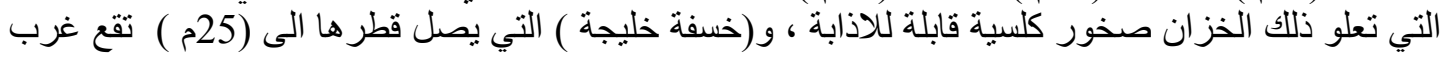
منخفض الجماعية، و( خسفة السالم ) تقع جنوب فيضة السالم يبلغ قطرها (14م ) و عمقها (5م) . صورة رقالم

\section{صورة (18)الخسفة الكبريتية التي تقع غرب منطقة الثبكة}

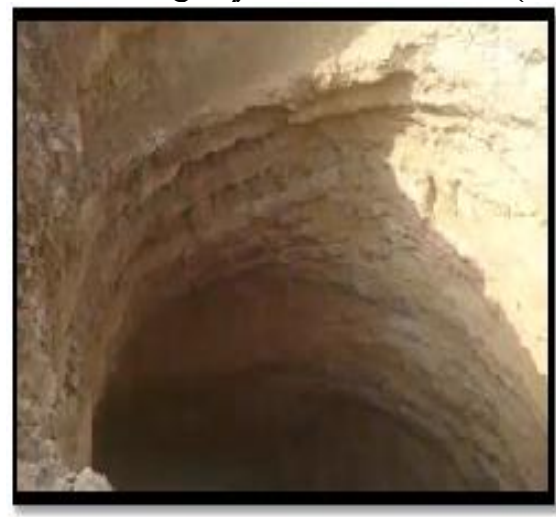

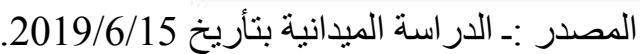

صورة (19) الخسفة الكبريتية التي تقع غرب منطقة الثبكة

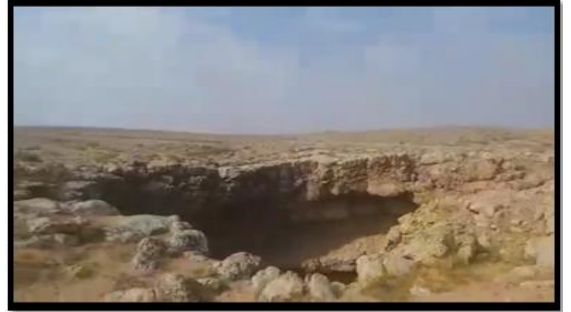

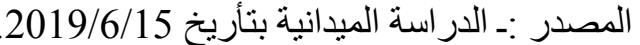

صورة (20) الخسفة المكرّع التي تقع جنوب شرق منطقة الشبكة 


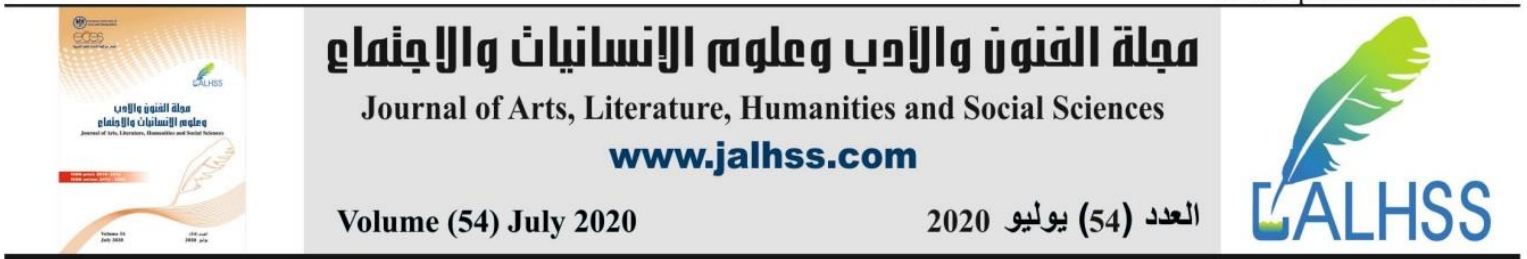

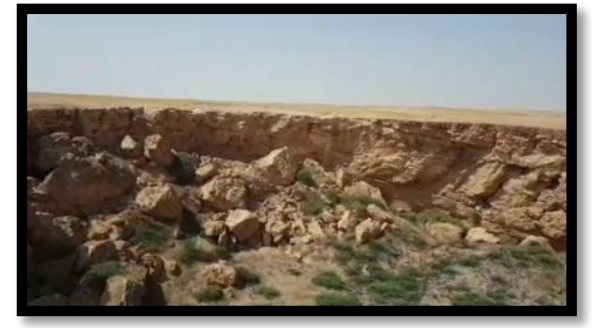

المصدر :- الدراسة الميدانية بتأريخ 2019/6/15.

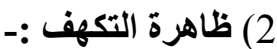

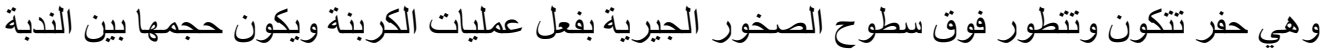

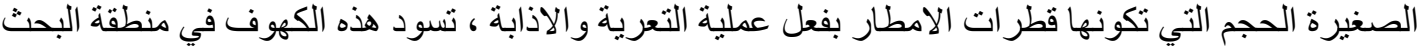

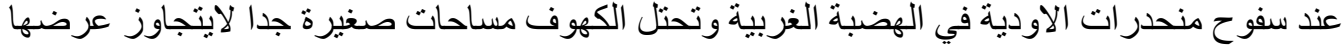

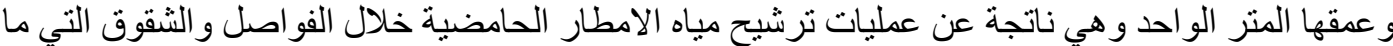

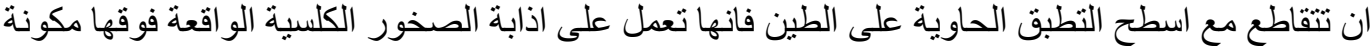

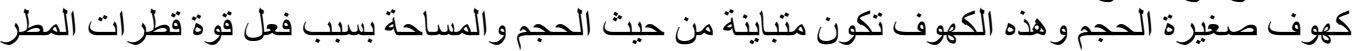

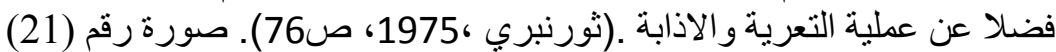
صورة (21) كهف في منطقة شرق الثبكة صنة

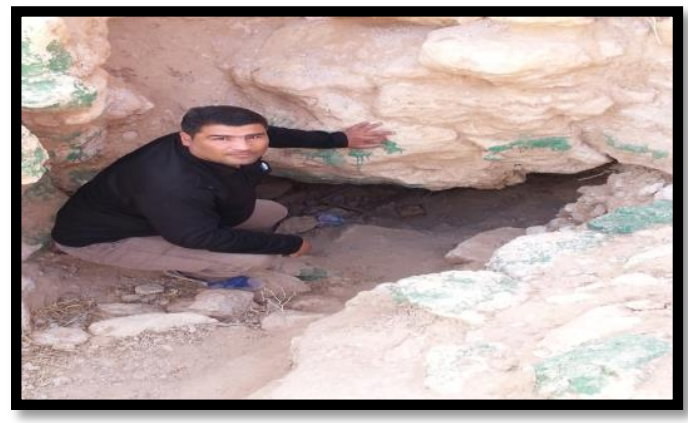

المصدر :- الدر اسة الميدانية بتأريخ 2019/2/6

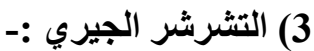
تنتشر هذه الظاهرة في المناطق الجيرية التي تمتاز بقلة الغطاء النباتي وتظرسها و عدم انتظامها وهي سطوح

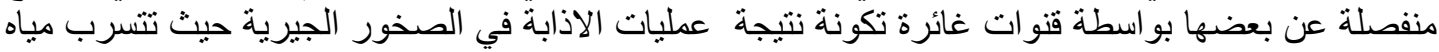

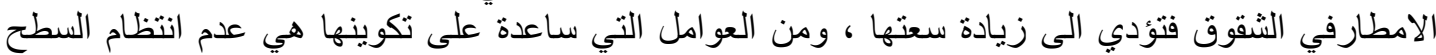

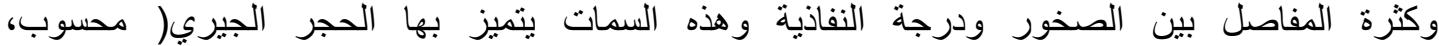

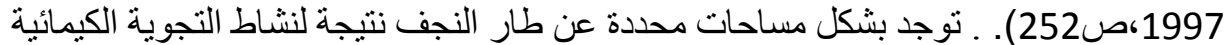

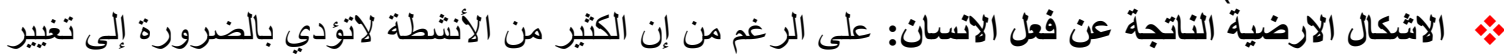

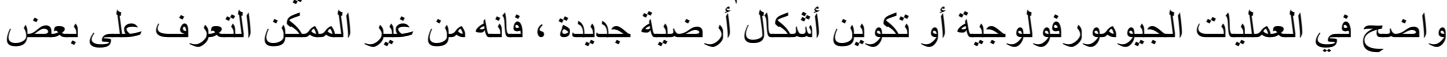

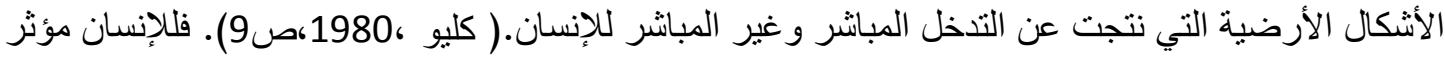

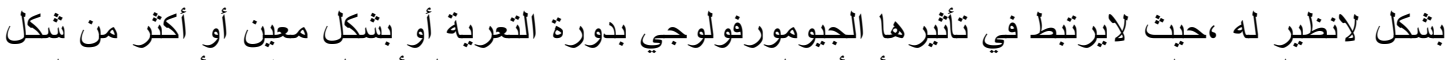

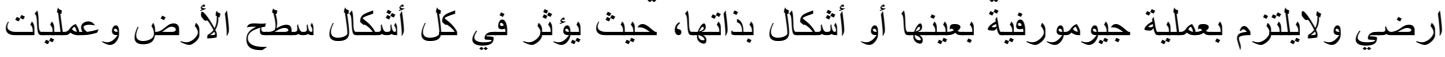

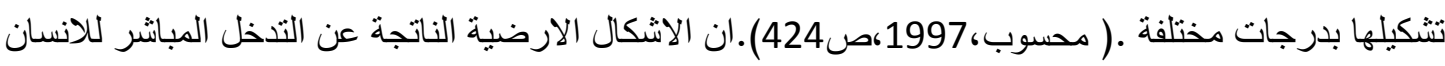

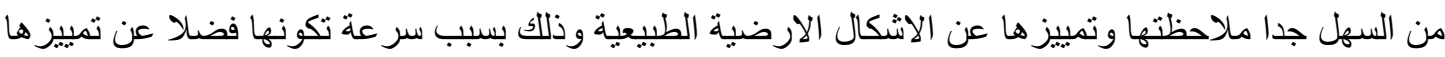

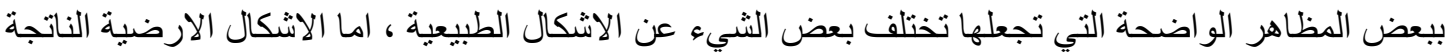

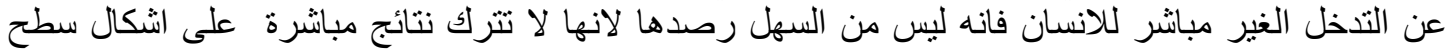




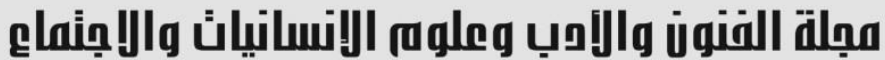

Journal of Arts, Literature, Humanities and Social Sciences www.jalhss.com

Volume (54) July 2020

العدد (54) يوليو 2020

الارض لكونها تحدث نتيجة التغيير البيئي بواسطة تكنولوجيا الانسان وبطريقة غير مقصودة ويمكن ملاحظة الإنة

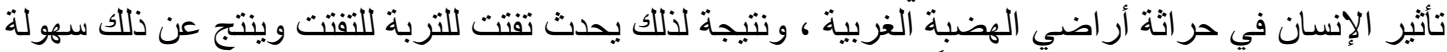
انجر افها وتعريتها بفعل الرياح ،فضلاً عن استغلاله للقتشرة الجبسية من خلال المقال المقالع المنتشرة شمال مدينة

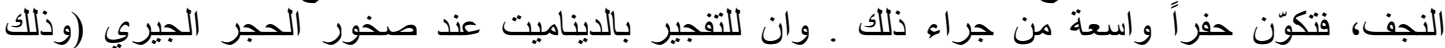

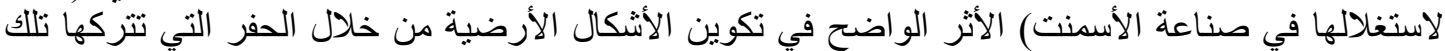

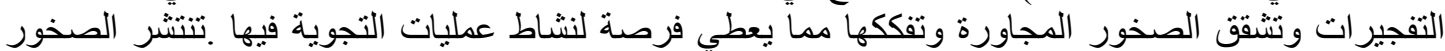

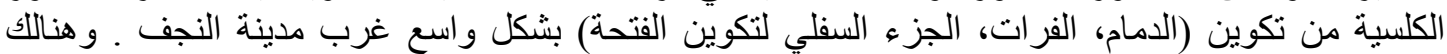

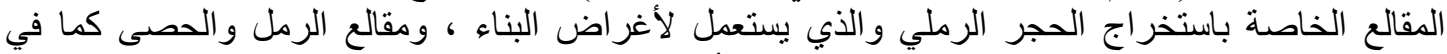

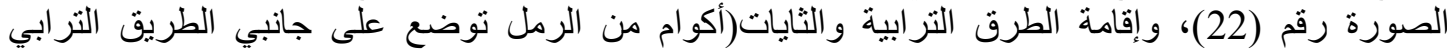

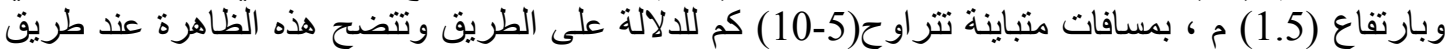

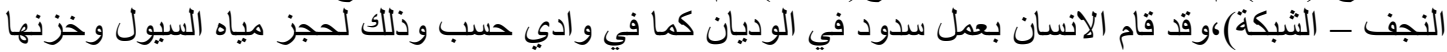

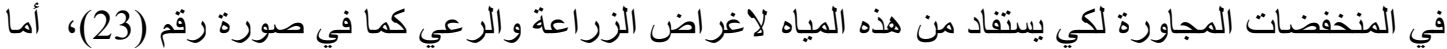

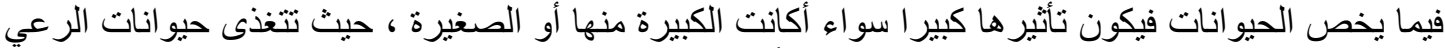

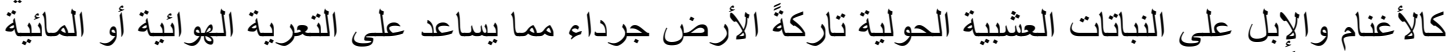

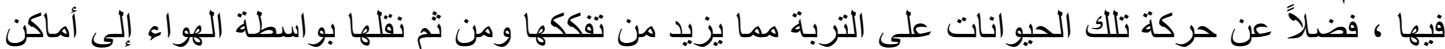

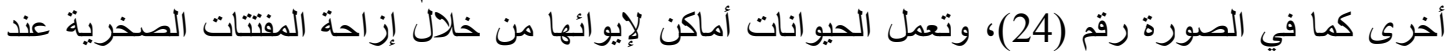

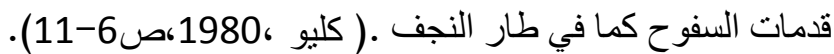
صورة (22)التعرية بفعل الانسان تمثل احد المقالع في منطقة البحث

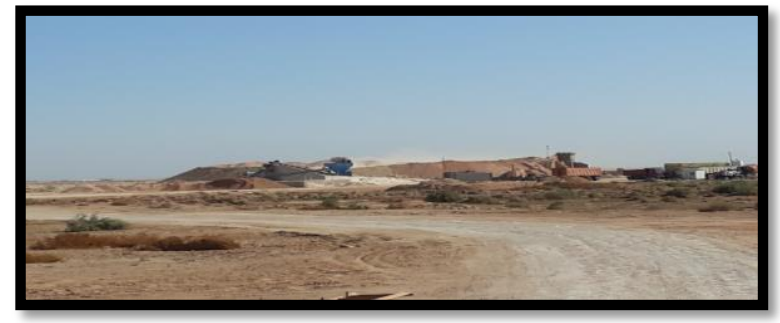

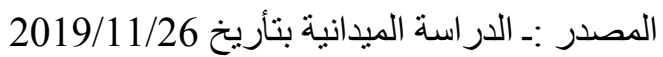
صورة (23) السد الذي اقيم على وادي حسب التب

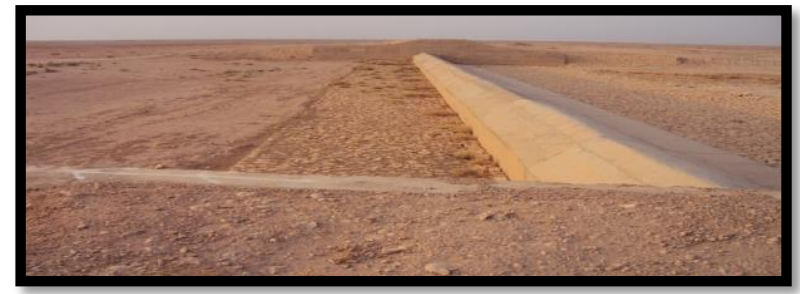

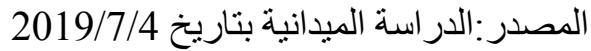
صورة (24)التعرية بفعل رعي الحيوانات في منطقة البحث 


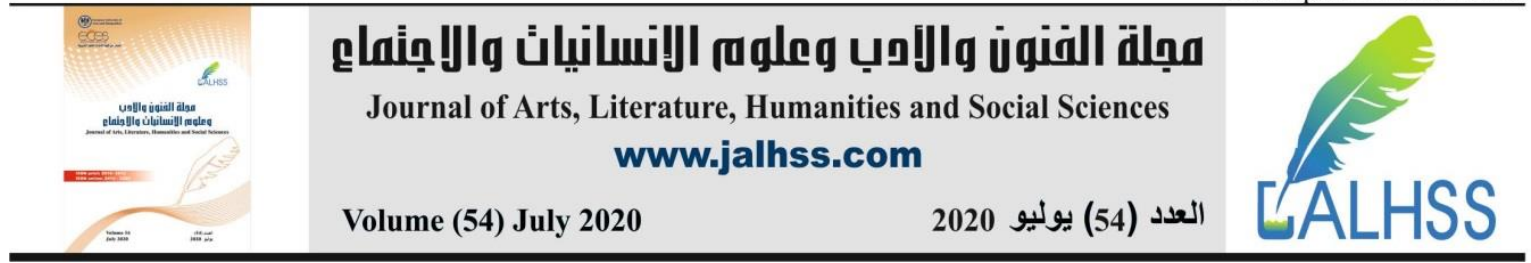

المصدر :- الدراسة الميدانية بتأريخ 2019/11/26

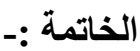

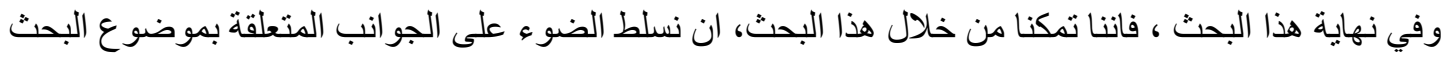

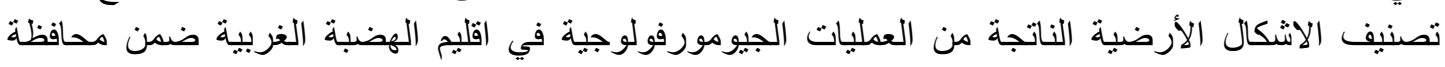

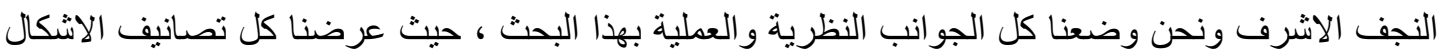

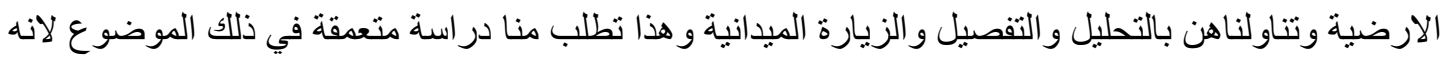

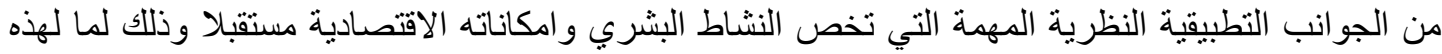

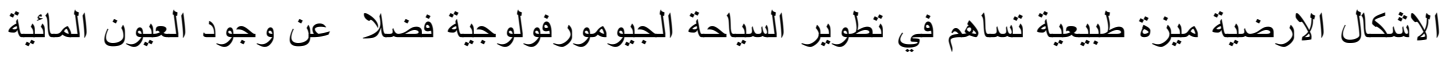

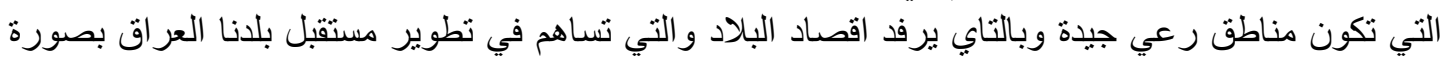

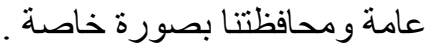
النتائج : النمان

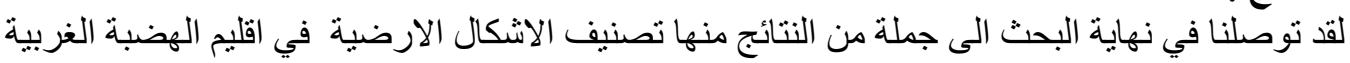
ومو اقع تو اجدها وماهي ناثير ها على البيئة و الانسان في المنطقة التئة

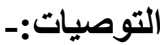
1) ظرورة اقامة در اسات جيومورفولوجية للمنطقة وبأتباع اساليب التطور الحديثة من اجل الاستفادة من طبيعة

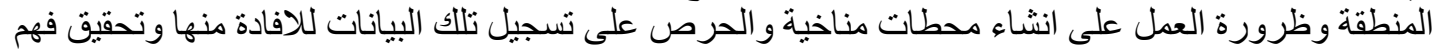

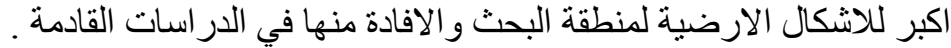

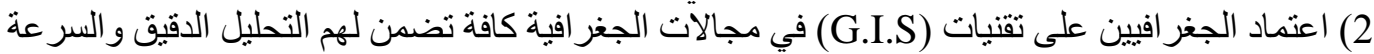

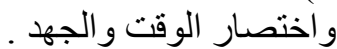

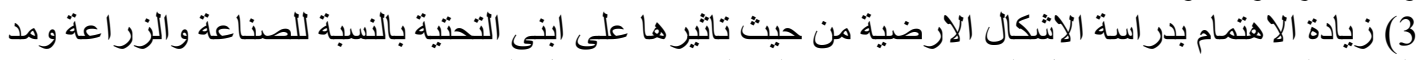

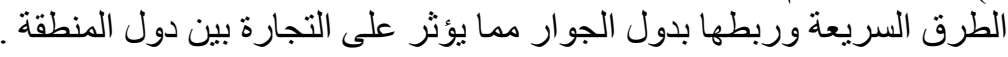

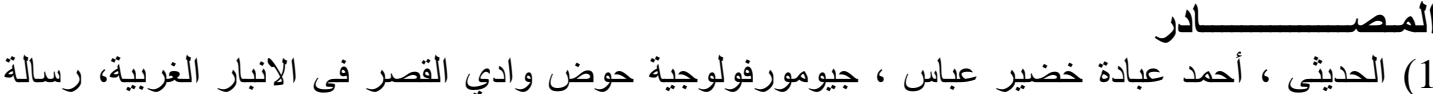

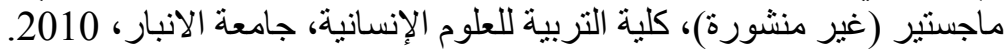

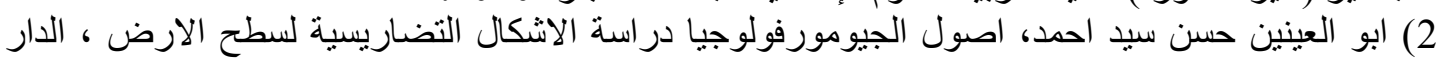

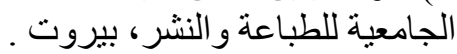

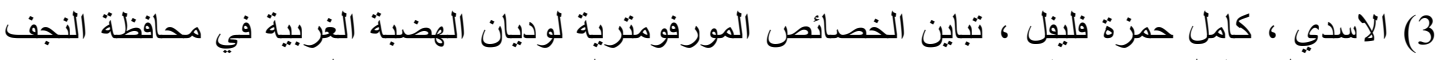

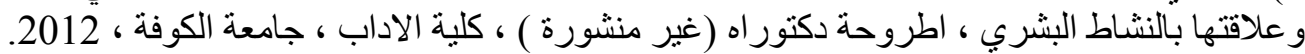

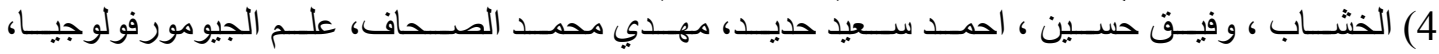

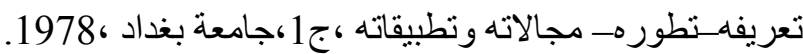

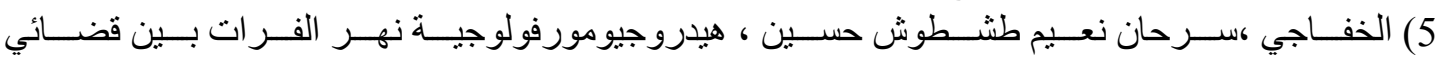

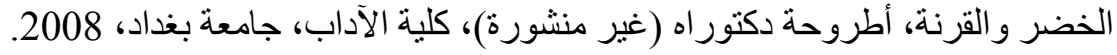

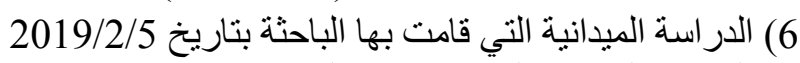

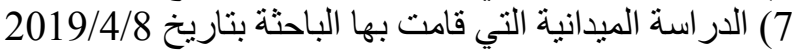

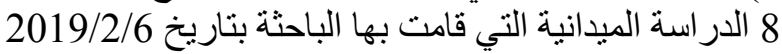

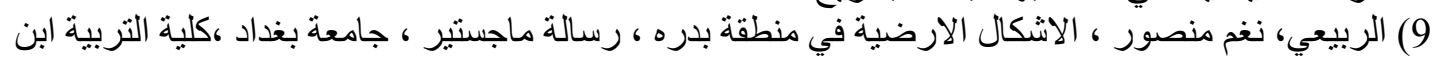

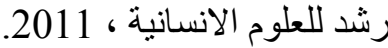

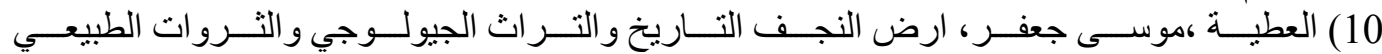
، 10،ؤسسة النبر اس للطباعة و النشر ، النجف الاشرف ، 2006. 


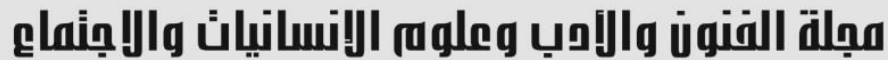

Journal of Arts, Literature, Humanities and Social Sciences www.jalhss.com

11) المحسن ،اسباهية يونس ،جيومورفولوجية الجزء الثمالي في منطقة الجزيرة في العراق، رسالة دكتور اه

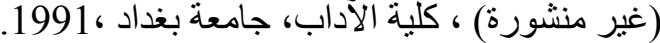

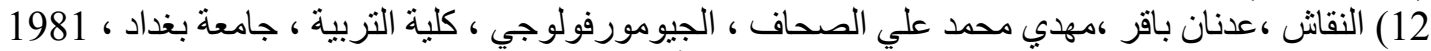

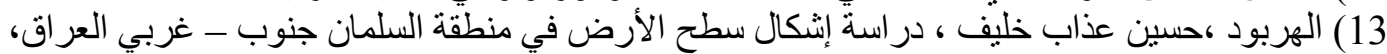

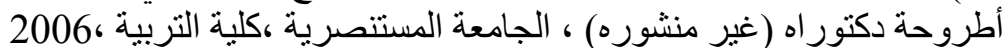

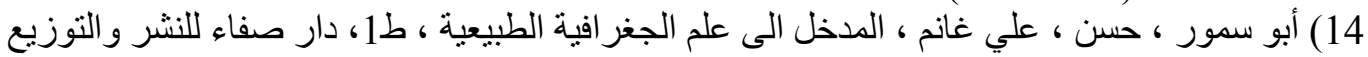

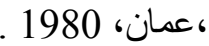

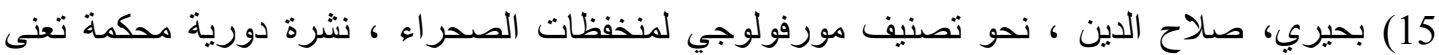

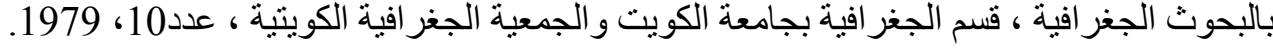

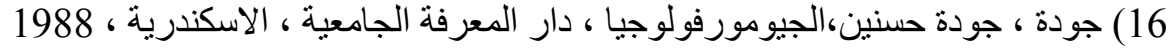

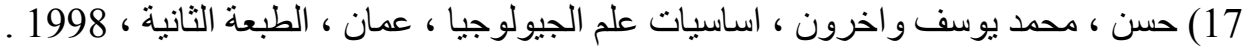
18) داود ، تغلب جرجيس ،أثكال سطح الأرض التطبيقي، الدار الجامعية للطباعة والنشر و الترجمة ، البصرة ، . 2002 ،

19) دي ثورنبري ،وليم، اسس الجيوموفولوجيا ، ترجمة وفيق حسن الخشاب ، الجزء الاول ، مطبعة جامعة

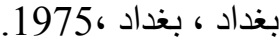
20) عبد المنعم ،سمير احمد عوض ، حمد محمود ، مقدمة في علم الرسوبيات، ط1، مكتبة الانجلو مصرية،

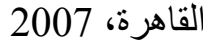

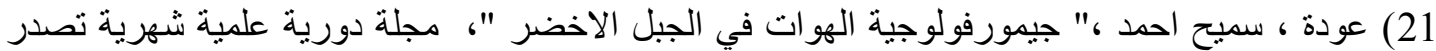

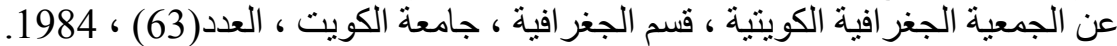

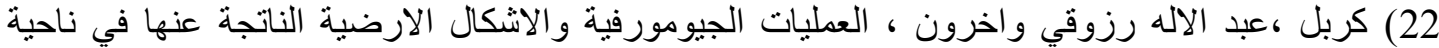

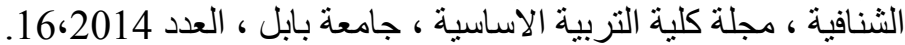

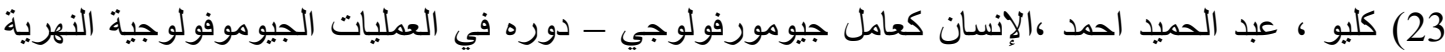
،نشرة دورية تعني بالبحوث الجغر افية ، الجمعية الجغرافية الكويتية وقسم الجغر افية ، جامعة الكويت، الكويت،

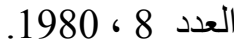

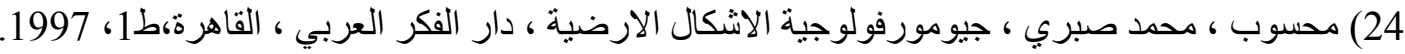
25) Cuchlaine A.M.K ing "Techniques in Geomorphology" Edward Amold1978,p58 


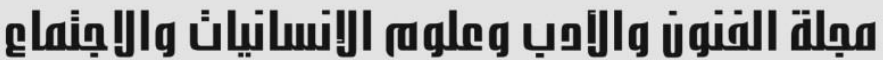

Journal of Arts, Literature, Humanities and Social Sciences www.jalhss.com

\section{References}

1) Al-Hadithi, Ahmad Obada Khudair Abbas, Geomorphology of Wadi Al-Qasr Basin in Western Anbar, MA (Unpublished), College of Education for Humanities, Anbar University, 2010.

2) Abu El-Enein Hassan Sayed Ahmed, The Origins of Geomorphology, Study of the Topographical Forms of Earth's Surface, University House for Printing and Publishing, Beirut.

3) Al-Asadi, Kamel Hamza Fleifel, Variation of Morphometric Characteristics of the Valley of the Western Plateau in the Governorate of Najaf and its Relationship with Human Activity, PhD Thesis (Unpublished), College of Arts, University of Kufa, 2012.

4) Al-Khashab, Wafik Hussain, Ahmed Saeed Hadid, Mahdi Muhammad Al-Sahaf, Geomorphology, Definition - Development - Fields and Applications, Part 1, University of Baghdad, 1978.

5) Al-Khafaji, Sarhan Naim Tashtush Hussain, Hydrogeomorphology of the Euphrates River between the Al-Khader and Al-Qurna Courts, PhD thesis (unpublished), College of Arts, University of Baghdad, 2008.

6) The field study conducted by the researcher on $5 / 2 / 2019$

7) The field study conducted by the researcher on $8 / 4 / 2019$

8 field study conducted by the researcher on $6 / 2 / 2019$

9) Al-Rubaie, Nagham Mansour, Geometric Shapes in Badrah, Master Thesis, University of Baghdad, Ibn Rushd College of Humanities, 2011.

10) Al-Attiyah, Musa Jaafar, Land of Najaf, History, Geological Heritage, and Natural Resources, 1st Edition, Al-Nebras Foundation for Printing and Publishing, Najaf Al-Ashraf, 2006.

11) Al-Mohsen, Asbahi Yunus, Geomorphology of the northern part in the Al-Jazeera region in Iraq, Ph.D. thesis (unpublished), College of Arts, University of Baghdad, 1991.

12) Al-Naqash, Adnan Baqer, Mahdi Muhammad Ali Al-Sahaf, Geomorphology, College of Education, University of Baghdad, 1981 13) Al-Harboud, Hussein Azab Khalif, Study of Earth's Surface Formation in Al-Salman Region, Southwest - Iraq, PhD Thesis (Unpublished), Al-Mustansiriya University College of Education, 2006

14) Abu Sammour, Hassan, Ali Ghanem, Introduction to Natural Geography, 1st edition, Safaa House for Publishing and Distribution, Amman, 1980.

15) Beheiry, Salah al-Din, Towards a Morphological Classification of Desert Deposits, A Concise Circular on Geographical Research, Department of Geography, Kuwait University and the Kuwaiti Geographical Society, No. 10, 1979.

16) Jouda, Jouda Hassanein, Geomorphology, University Knowledge House, Alexandria, 1988.

17) Hassan, Muhammad Yusuf and others, Fundamentals of Geology, Amman, second edition, 1998. 


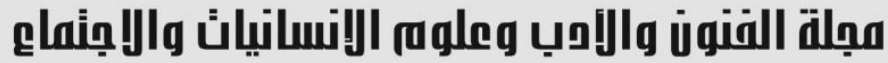 \\ Journal of Arts, Literature, Humanities and Social Sciences www.jalhss.com

18) Dawood, Surpassing Zarzis, Applied Surface Forms, University House for Printing, Publishing and Translation, Basra, 2002.

19) De Thornberry, William, Principles of Geomemology, Translated by Wafik Hassan Al-Khashab, Part One, Baghdad University Press, Baghdad, 1975.

20) Abdel-Moneim, Samir Ahmed Awad, Hamad Mahmoud, Introduction to Sedimentology, 1st edition, The Anglo-Egyptian Library, Cairo, 2007.

21) Odeh, Samih Ahmed, "Geomorphology of Hawes in the Green Mountain", a monthly scientific journal published by the Kuwaiti Geographical Society, Geography Department, Kuwait University, No. (63), 1984.

22) Karbel, Abd al-Ilah Razouki et al., Geomorphic Processes and the Earthly Shapes Resulting from them in the Al-Shanafiyah District, Journal of the College of Basic Education, University of Babylon, No. 16,2014.

23) Cleo, Abdul Hamid Ahmed, Human as a Geomorphologist - Its Role in River Geomorphological Operations, Periodical Bulletin concerned with Geographical Research, Kuwait Geographical Society and Department of Geography, Kuwait University, Kuwait, No. 8, 1980.

24) Mahsoub, Muhammad Sabri, Geomorphology of Earth Forms, Dar Al-Fikr AlArabi, Cairo, Ed.1, 1997.

25) Cuchlaine A.M.K ing "Techniques in Geomorphology" Edward Amold1978, p58. 